\title{
Development of an AC Module System Final Technical Report
}

15 June 2012 


\section{Contents}

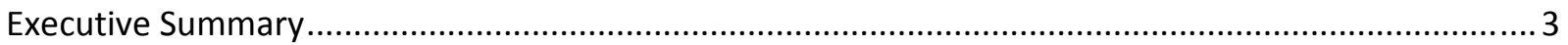

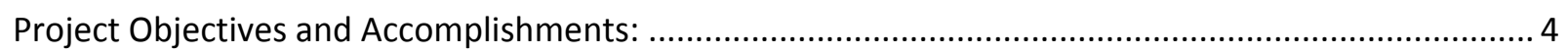

Summary of Project Activities \& Accomplishments......................................................................... 4

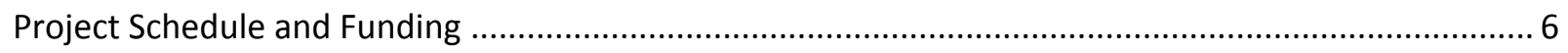

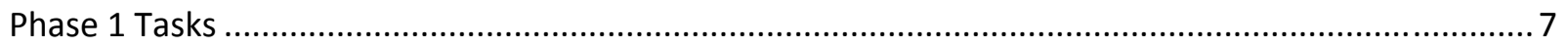

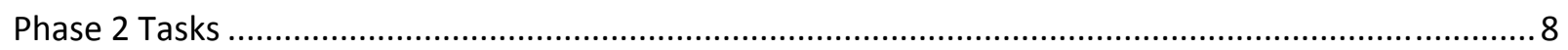

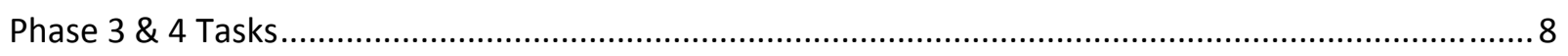

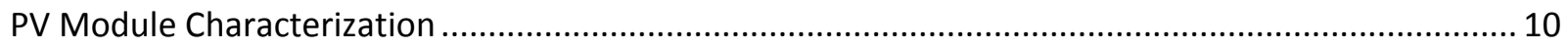

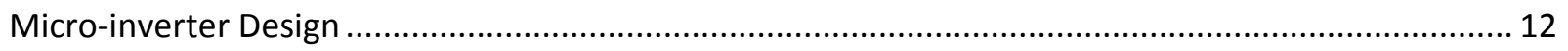

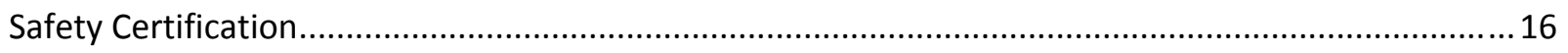

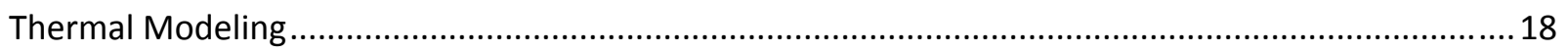

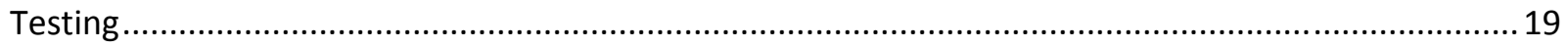

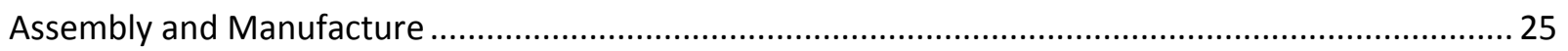

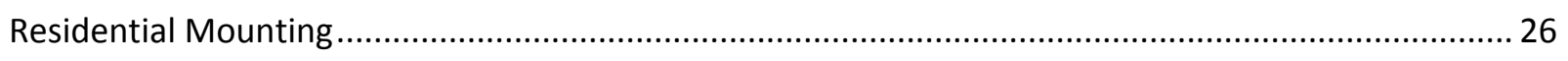

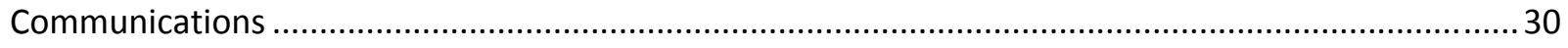

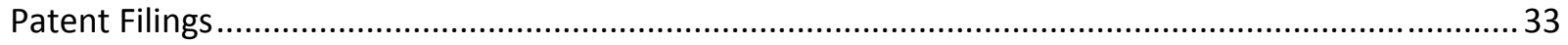

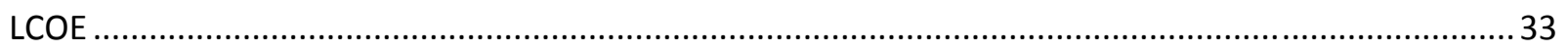

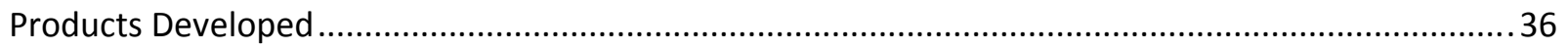




\section{Technology Pathway Partnership Final Technical Report}

Project Title:

Recipient:

Award Number:

Recipient Contacts:

DOE Project Team:
Development of an AC Module System

GreenRay, Inc.

DE-FC36-07G017050

Miles Russell

Suparna Kadam

Phone: 781-962-9878

Phone: 732-407-7869

Fax: 978-467-1301

Email: miles.russell@

greenraysolar.com

DOE Field Contracting Officer

DOE Field Project Officer

Technical Monitor
Fax: 732-651-0759

Email: suparna.kadam@ greenraysolar.com

- Nicole Blackstone

- Jim Payne

- $\quad$ Sig Gonzalez

\section{Executive Summary}

The GreenRay Inc. program focused on simplifying solar electricity and making it affordable and accessible to the mainstream population. This was accomplished by integrating a solar module, micro-inverter, mounting and monitoring into a reliable, "plug and play" AC system for residential rooftops, offering the following advantages:

- Reduced Cost: Reduction in installation labor with fewer components, faster mounting, faster wiring.

- Maximized Energy Production: Each AC Module operates at its maximum, reducing overall losses from shading, mismatch, or module downtime.

- Increased Safety. Electrical and fire safety experts agree that AC Modules have significant benefits, with no energized wiring or live connections during installation, maintenance or emergency conditions.

- Simplified PV for a Broader Group of Installers. Dramatic simplification of design and installation of a solar power system, enabling faster and more efficient delivery of the product into the market through well-established, mainstream channels. This makes solar more accessible to the public.

- Broadened the Rooftop Market: AC Modules enable solar for many homes that have shading, split roofs, or obstructions. In addition, due to the smaller building block size of $200 \mathrm{~W}$ vs. $1000 \mathrm{~W}$, homeowners with budget limitations can start small and add to their systems over time.

Through this DOE program GreenRay developed the all-in-one AC Module system with an integrated PV Module and microinverter, custom residential mounting and performance monitoring. Development efforts took the product from its initial concept, through prototypes, to a commercial product sold and deployed in the residential market. This pilot deployment has 
demonstrated the technical effectiveness of the AC Module system in meeting the needs and solving the problems of the residential market. While more expensive than the traditional central inverter systems at the pilot scale, the economics of AC Modules become more and more favorable as the product matures and is made in high volumes. GreenRay's early customers have been highly enthusiastic about the AC Module system benefits.

\section{Project Objectives and Accomplishments:}

The objective of the GreenRay Inc. program was to develop an AC module system that integrates a PV module, micro-inverter, mounting and monitoring, and is focused on the residential PV market. The target attributes of the AC module system were:

- Simpler to design systems

- Safer for installer/users

- Lower cost

- Higher reliability

These attributes contribute to realizing the DOE's Levelized Cost of Energy (LCOE) targets by 2015.

The products developed through this program met all of these targets in the following way:

- Simpler to design systems - no need to match module strings to central inverter, one size fits all, unique mounting system simplified the design for nonmonolithic arrays on rootops

- Safer for installer/users - system remains de-energized until final connection to the grid and is easily understood by installers and inspectors. This is contrasted by the high DC voltages of centralized-inverter based systems.

- Lower cost - the integrated inverter and quick mounting lowered installation time and cost.

- $\quad$ Higher reliability - innovative inverter design utilizes film capacitors not electrolytics and is designed for a 30-year life.

\section{Summary of Project Activities \& Accomplishments}

There are five primary elements of the AC Module System shown below: micro-inverter, module frame, mounting system, quick connector and cable, and data communications elements, in addition to business development activity. This simplified block diagram is intended to show the inherent inter-dependency and inter-relationship of these various elements; none of these elements can be developed in isolation of the others, as they are intimately linked. 


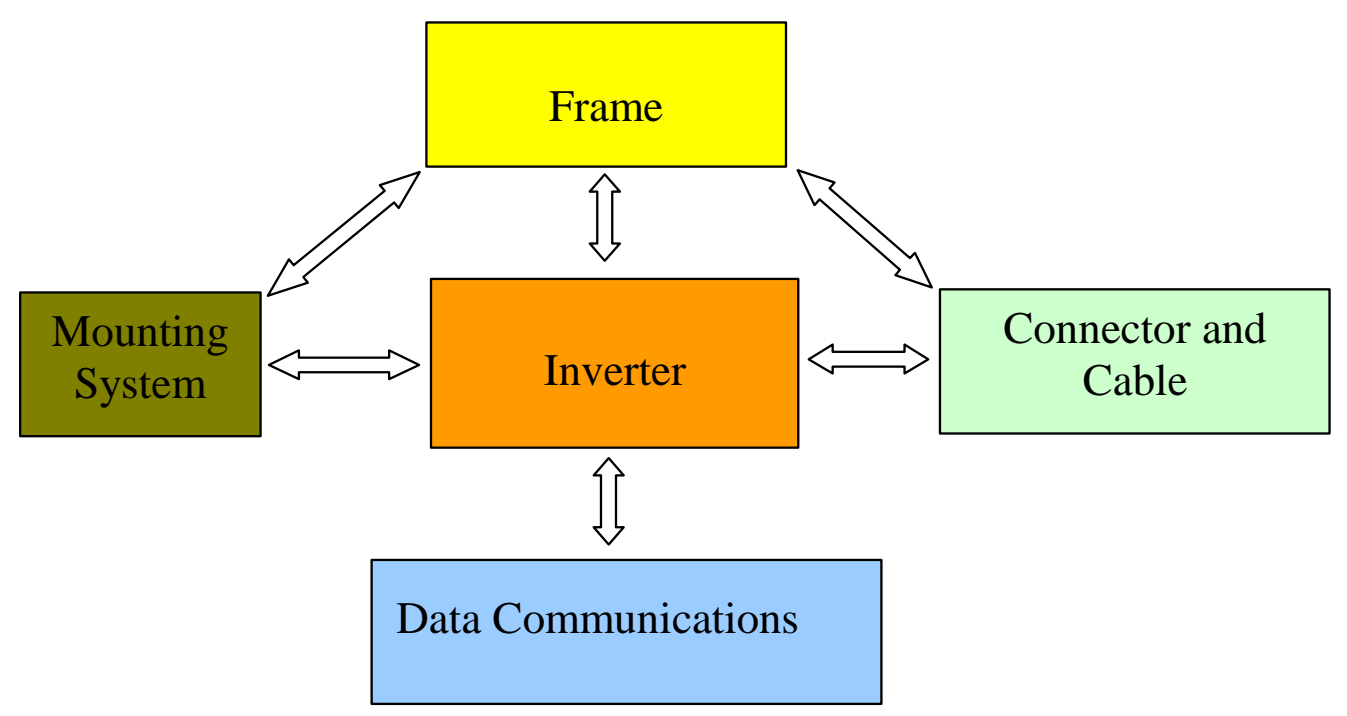

The project spanned a period of 5 years and had four development phases.

Phase 1: 1 January $2007-31$ July 2008

Initial development of the inverter, frame, mounting system, connector/cable, and communications for the AC Module

Phase 2: 1 Aug 2008 - 28 February 2009

Design revisions and modifications of the inverter, frame, mounting system, connector/cable, and communications for the AC Module

Phase 3: 1 March - 31 August 2009

Testing and certifications of the AC Module. Planning and preparation for manufacturing and market channel and launch.

Phase 4: 1 September 2009 - 31 December 2011

Testing and certifications of the AC Module. Commercial manufacturing and market launch.

While there were several technical and business hurdles along the way that extended the original three-year timeline, these were all overcome and the project was highly successful. GreenRay began the program as a nascent, startup company with nothing more than concepts for the AC Module System. Throughout the life of this program, those ideas crystallized into designs, prototypes, and finally commercially manufactured products which were sold into the residential PV market. The specific tasks for each phase along this journey are summarized in the tables that follow. 
DE-FC36-07G017050

Development of an AC Module System

GreenRay, Inc.

Project Schedule and Funding

\begin{tabular}{|c|c|c|}
\hline $\begin{array}{c}\text { Budget } \\
\text { Period }\end{array}$ & Start & Finish \\
\hline 1 & 1 Jan 2007 & 31 Jul 2008 \\
\hline 2 & 1 Aug 2008 & 28 Feb 2009 \\
\hline 3 & 1 Mar 2009 & 31 Aug 2009 \\
\hline 4 & 1 Sep 2009 & 31 Dec 2011 \\
\hline Overall & 1 Jan 2007 & 31 Dec 2011 \\
\hline
\end{tabular}

\begin{tabular}{|r|c|}
\hline \multicolumn{1}{|l|}{ Funding } & Amount \\
\hline DOE Funding & $\$ 3,333,200.00$ \\
\hline $\begin{array}{l}\text { GreenRay Cost } \\
\text { Share }\end{array}$ & $\$ 4,394,136.20$ \\
\hline Project Total & $\$ 7,727,336.20$ \\
\hline
\end{tabular}


DE-FC36-07GO17050

Development of an AC Module System

GreenRay, Inc.

Phase 1 Tasks

\begin{tabular}{|c|c|c|c|}
\hline $\begin{array}{c}\text { Task } \\
\text { Number }\end{array}$ & Task Description & $\begin{array}{c}\text { Date } \\
\text { Complete }\end{array}$ & Accomplishments \\
\hline 1.1 & Module Characterization & May ‘07 & Characterization complete by Sandia \\
\hline 1.2 & $\begin{array}{l}\text { Complete AC Module } \\
\text { Specifications }\end{array}$ & June ‘07 & $\begin{array}{l}\text { Specs are complete, but subject to further } \\
\text { refinement }\end{array}$ \\
\hline 1.3 & Alpha Micro-inverter Design & July ‘07 & $\begin{array}{l}\text { Design study finished; Alpha circuit } \\
\text { designed }\end{array}$ \\
\hline 1.4 & $\begin{array}{l}\text { Alpha I/II Micro-inverter } \\
\text { Prototype Construction }\end{array}$ & Oct ‘07 & Alpha II constructed \\
\hline 1.5 & Alpha Micro-inverter Bench Test & Apr '08 & $\begin{array}{l}\text { Operated and tested at full power, UL } \\
\text { preliminary investigation complete. Sandia } \\
\text { Advanced Packaging Group reliability } \\
\text { review complete. }\end{array}$ \\
\hline 1.6 & $\begin{array}{l}\text { Alpha Micro-inverter thermal } \\
\text { evaluations }\end{array}$ & Jun ‘08 & $\begin{array}{l}\text { Thermal time constant of inverter } \\
\text { characterized. Plans for thermal stress } \\
\text { tests complete. Task continues in Phase II. }\end{array}$ \\
\hline 1.7 & $\begin{array}{l}\text { Operation under abnormal } \\
\text { conditions }\end{array}$ & Apr ‘08 & Task continues in Phase II \\
\hline 1.8 & AC Module Frame & Jun ‘08 & $\begin{array}{l}\text { SLA prototypes fabricated; structurally } \\
\text { analyzed }\end{array}$ \\
\hline 1.9 & $\begin{array}{l}\text { Development of Quick } \\
\text { Connectors }\end{array}$ & Jun ‘08 & Concept generated, prototypes fabricated \\
\hline 1.10 & $\begin{array}{l}\text { Develop Residential Mounting } \\
\text { System }\end{array}$ & Jun ‘08 & $\begin{array}{l}\text { Mounting component prototypes } \\
\text { fabricated. Evaluated and deployed on in } \\
\text { house test roof. }\end{array}$ \\
\hline 1.11 & Wireless Data Components & Jun ‘08 & $\begin{array}{l}\text { Data communications elements } \\
\text { demonstrated. Data access from hand held } \\
\text { device operational. }\end{array}$ \\
\hline 1.12 & $\begin{array}{l}\text { Beta I micro-inverter fabrication } \\
\text { and test }\end{array}$ & & $\begin{array}{l}\text { UL and Sandia and DOE reviews lead to } \\
\text { Beta I. Beta } 1 \text { design includes change in } \\
\text { topology, and shift from } 400 \mathrm{~W} \text { to } 200 \mathrm{~W} \\
\text { output. Design in progress, Continues into } \\
\text { Phase } 2\end{array}$ \\
\hline 1.13 & $\begin{array}{l}\text { Beta II micro-inverter fabrication } \\
\text { and testing }\end{array}$ & & Continues in Phase 2 \\
\hline
\end{tabular}


DE-FC36-07GO17050

Development of an AC Module System

GreenRay, Inc.

\begin{tabular}{|c|c|c|}
\hline 1.14 & $\begin{array}{l}\text { Complete Wireless Elements for } \\
\text { Beta1 }\end{array}$ & Continues in Phase 2 \\
\hline 1.15 & $\begin{array}{l}\text { Begin Evaluation and Analysis of } \\
\text { Mounting System }\end{array}$ & Continues in Phase 2 \\
\hline 1.16 & $\begin{array}{l}\text { Create Plan to Finalize and } \\
\text { Fabricate Quick Connectors }\end{array}$ & Continues in Phase 2 \\
\hline 1.17 & $\begin{array}{l}\text { Market and Channel } \\
\text { Development }\end{array}$ & $\begin{array}{l}\text { Business plan preparation ongoing. } \\
\text { Discussions on-going with prospective } \\
\text { partners. Continues in Phase } 2\end{array}$ \\
\hline
\end{tabular}

\section{Phase 2 Tasks}

\begin{tabular}{|c|c|c|c|}
\hline $\begin{array}{l}\text { Task } \\
\text { Number }\end{array}$ & Task Description & $\begin{array}{l}\text { Date } \\
\text { Complete }\end{array}$ & Accomplishments \\
\hline 2.1 & $\begin{array}{l}\text { Frame Modifications and } \\
\text { Residential Mounting } \\
\text { System }\end{array}$ & Feb ‘09 & $\begin{array}{c}\text { Frame modifications designed, mounting } \\
\text { system revisions designed. Design and hands } \\
\text { on installation feedback incorporated from } 2 \\
\text { installer partners. }\end{array}$ \\
\hline 2.2 & Quick Connectors and Cable & Feb ‘09 & $\begin{array}{c}\text { One source identified: second source being } \\
\text { developed }\end{array}$ \\
\hline 2.3 & $\begin{array}{l}\text { Beta I Inverter and AC } \\
\text { Module I }\end{array}$ & Feb ‘09 & Prototypes operational on GreenRay's roof \\
\hline 2.4 & $\begin{array}{l}\text { Beta II Inverter and AC } \\
\text { Module II }\end{array}$ & Jun ‘09 & $\begin{array}{l}\text { Prototypes built and sent to Sandia and UL for } \\
\text { testing. }\end{array}$ \\
\hline 2.5 & $\begin{array}{l}\text { Data Monitoring and } \\
\text { Communications Elements }\end{array}$ & Feb ‘09 & $\begin{array}{l}\text { AC Module prototypes reporting via powerline } \\
\text { and uploading to web }\end{array}$ \\
\hline 2.6 & $\begin{array}{l}\text { AC Module Business } \\
\text { Development }\end{array}$ & Feb ‘09 & Biz plan delivered to DOE in Feb \\
\hline
\end{tabular}

\section{Phase 3 \& 4 Tasks}

\begin{tabular}{|c|l|c|c|}
\hline $\begin{array}{c}\text { Task } \\
\text { Number }\end{array}$ & \multicolumn{1}{|c|}{ Task Description } & $\begin{array}{c}\text { Date } \\
\text { Complete }\end{array}$ & Accomplishments \\
\hline $\mathbf{3 . 6}$ & Inverter Recognition & Jun'10 & Done \\
\hline $\mathbf{3 . 7}$ & Stress Testing & Dec'10 & HALT completed \\
\hline
\end{tabular}


DE-FC36-07G017050

Development of an AC Module System

GreenRay, Inc.

\begin{tabular}{|c|l|c|c|}
\hline 3.8 & Manufacturing Plan & Feb '10 & $\begin{array}{c}\text { Agreements with module vendor and } \\
\text { contract manufacturer in place. }\end{array}$ \\
\hline $\mathbf{3 . 9}$ & Product Literature & Feb '10 & $\begin{array}{c}\text { Brochures, Spec Sheets, and website done. } \\
\text { See www.greenraysolar.com }\end{array}$ \\
\hline $\mathbf{4 . 1}$ & $\begin{array}{l}\text { AC Module Safety } \\
\text { Certification }\end{array}$ & May '10 & Done \\
\hline $\mathbf{4 . 2}$ & Long-Term Testing & $\begin{array}{l}\text { Mec'11 } \\
\text { channel development }\end{array}$ & $\begin{array}{c}\text { Damp heat conducted by TUV. Internal } \\
\text { chamber and field testing on-going }\end{array}$ \\
\hline $\mathbf{4 . 4}$ & Market Introduction & Dec '11 & $\begin{array}{c}\text { Relationships built with several installers in } \\
\text { the US. Sales and installation training } \\
\text { conducted. }\end{array}$ \\
\hline
\end{tabular}




\section{PV Module Characterization}

One of the first tasks GreenRay undertook was modeling. Two Sanyo HIT PV modules were shipped to Sandia National Laboratories for outdoor evaluation and characterization at the Photovoltaic System Evaluation Laboratory. Sandia installed the two PV modules at PSEL with instrumentation and monitored them for approximately six weeks. After more than 4,000 "observations" or data points, the data were analyzed to determine ratings for the PV modules under a range of typical meteorological conditions. In addition, the coefficients describing the change of PV module I-V characteristics with temperature and irradiance were also derived and documented. The derived coefficients allowed us to then model the PV module accurately using Sandia's 5-point I-V curve modeling algorithms.

\section{MA BO IV Curve}

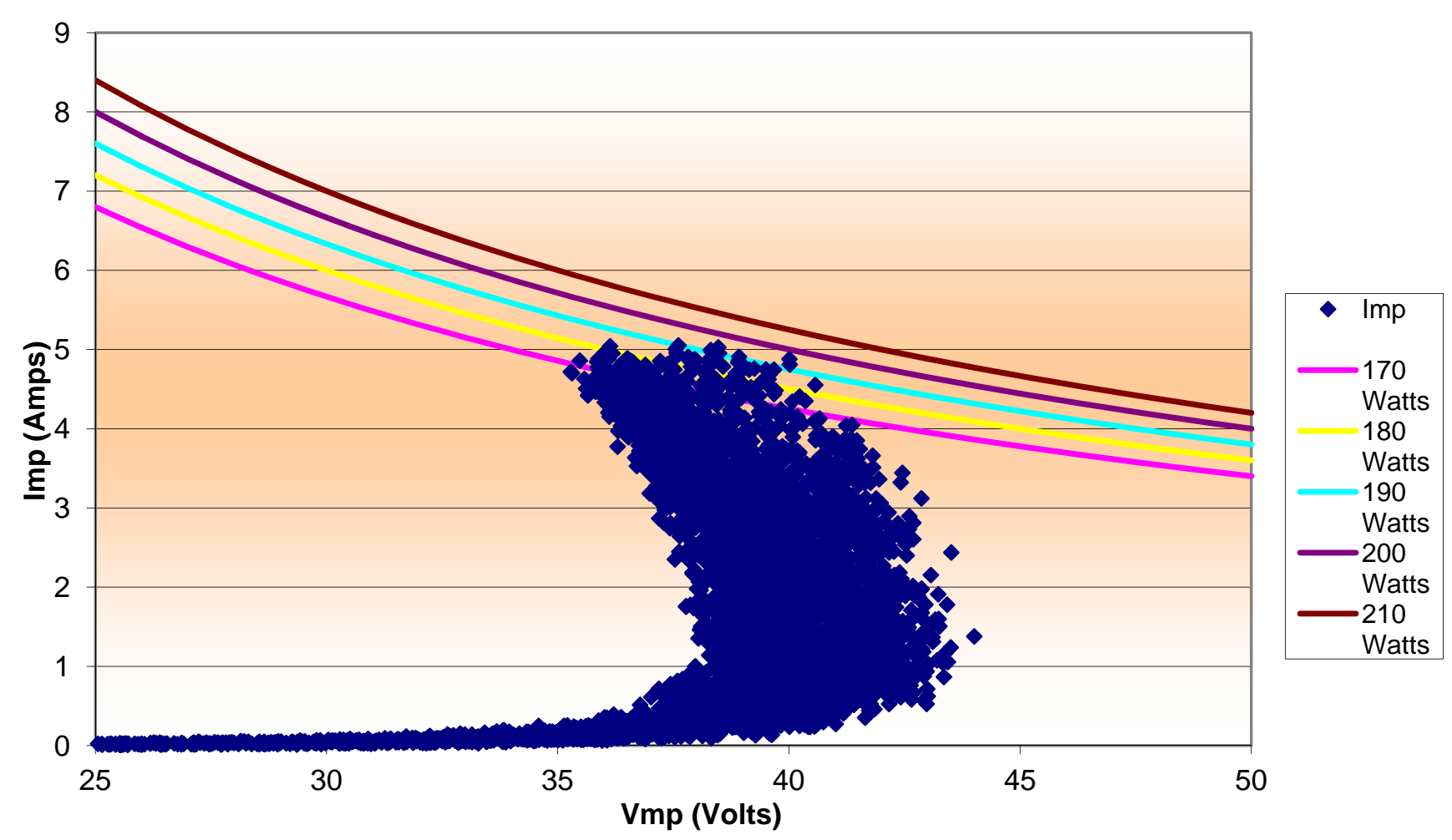

Simulated hour-by-hour values of module Vmp and Imp in the Boston climate. 
DE-FC36-07G017050

Development of an AC Module System

GreenRay, Inc.

\section{MA_BO Vmp Curve}

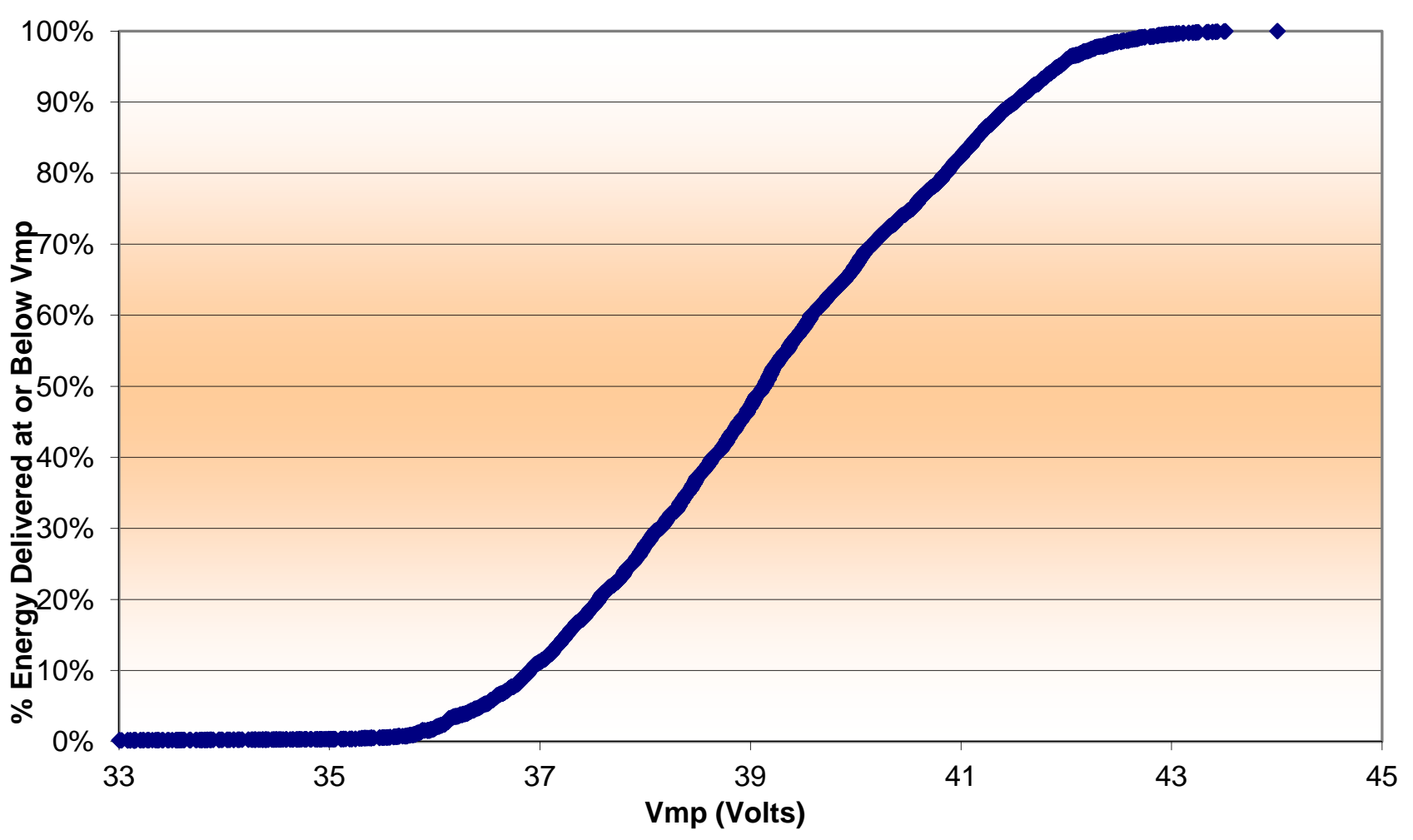

Sorted, simulated hour-by-hour values in the Boston climate

GreenRay used these models to simulate the performance of the Sanyo HIT PV modules in various climates, and establish the range of module current, voltage and power output and thereby help to optimize the micro-inverter for these modules. 


\section{Micro-inverter Design}

Work on the design of the micro-inverter began with a review of the requirements and specifications, followed by a comprehensive study of circuits and topologies that might be used. Suitable power electronic and other circuit components were identified and their characteristics summarized. Samples were obtained. GreenRay generated a model for the power circuit of the micro-inverter for the different circuit topologies under consideration, and exercised the model to estimate efficiency and parts cost. Among the variables studied parametrically for the several different inverter circuit designs were dc input voltage range, output ac voltage and the inverter power rating. Based on the results of the study, we selected a circuit topology that had the potential to meet our lifetime, efficiency and cost targets.

For the selected topology and configuration (input dc voltage, output ac voltage and inverter power rating), a circuit was designed. GreenRay's initial concept was a 400-Watt micro-inverter that would serve two 200-Watt Sanyo PV modules. However, over the course of the project and with feedback from the DOE and advisors, our focus shifted to a 200-Watt inverter operating with a single PV module.

GreenRay's micro-inverter is designed to operate reliably for the 25-year economic lifetime of a PV module. Accordingly we have eliminated known life-limiting circuit elements, such as electrolytic capacitors, that are commonly found in inverters. One of the fundamental premises of our approach has been the complete elimination of electrolytic capacitors from the design. This prohibition applies not only to the large storage capacitance that is inherently needed in a $\mathrm{dc} / \mathrm{ac}$ inverter, but also to the smaller circuits, such as the internal power supply for the control electronics. Note that this applies also to the entire class of electrolyte-type capacitors such as tantalum capacitors.

The problem with electrolytic capacitors is not necessarily that they have low reliability, but rather that they have a known wear-out mechanism which causes end of life. Electrolytic capacitors may not see high failure rates in an inverter until later in life, when a very large percentage of the inverter population starts to fail over a relatively short period of time. The time-to-wear-out for an electrolytic capacitor is dependent upon the environment in which it operates. The wear-out mechanism is loss of electrolyte, which happens with temperature and time. As electrolyte is lost, internal resistance increases, which increases internal self heating, which further increases the rate of electrolyte loss in a positive feedback cycle. End-of-life failure of electrolytic capacitors is typically quite dramatic and makes design of an inverter more difficult to pass safety testing.

As a result, and out of an abundance of caution, we have chosen to only use ceramic and metalized film capacitors. Unlike electrolytic capacitors, metalized film capacitors do not have a limiting wear out mechanism. End-of-life for film capacitors is typically defined as a loss of $2 \%$ of initial capacitance, compared with loss of $20 \%$ capacitance for electrolytic capacitors. If the inverter is designed to function with $20 \%$ loss of capacitance, then film capacitor life can be nearly $10 x$ the design lifetime listed on the datasheet. Film capacitors are also more rugged than electrolytic capacitors because they can withstand much higher voltage surges, relative to their voltage rating, and they have self-healing properties inherent in their construction. 
Opto-coupler devices are not used in GreenRay's inverter. These devices are used in many consumer power-electronic products, however, they typically exhibit very wide variation in their characteristics over wide temperature extremes. In the consumer-product environment, the range of operating temperatures is quite limited and this is not a significant problem. In contrast, the range of temperatures experienced by the micro-inverter in an AC Module is extreme and as a result we have eliminated opto-couplers from the inverter.

It is well known that in order to achieve high product reliability, there must be margin between internal component ratings and the final product rating. We utilized the Jet Propulsion Laboratory De-Rating Guidelines (JPL Derating Guidelines, Jet Propulsion Laboratory, Electronic Parts Engineering Office 514) as a guide to the component de-rating process. This 20-page document provides engineering details on how to apply de-rating. The scope of the document states: "This document provides guidelines and recommendations for de-rating of electronic parts used in JPL spaceflight hardware." While GreenRay is not intending to build hardware for spaceflight application, we strongly believe it is useful to draw guidance from their lessons learned.

The guide further states: "De-rating of a part is the intentional reduction of its electrical, mechanical and thermal stresses for the purpose of providing a safety margin between the applied stress and the actual demonstrated limit of the part capabilities. The de-rating policy established herein is intended to reduce the occurrence of stress-related failures and help assure long-term reliability."

For example, power MOSFETs are to be de-rated by 0.75 for current and voltage ratings and 0.50 for power rating, with a maximum junction temperature of $125^{\circ} \mathrm{C}$, or $40^{\circ} \mathrm{C}$ below manufacturer specified maximum temperature. Ceramic capacitors have a voltage de-rating factor of 0.60 , meaning that a capacitor intended to be operated at a maximum of 12 Volts must have a rating of at least 20 Volts $(12 / 20=0.60)$. Electrolytic capacitors are not even listed in the guide. Every component in the inverter has been reviewed to ensure that all components meet reasonable design safety margins.

In addition GreenRay contracted with the Advanced Packaging Group at Sandia National Laboratories to conduct a comprehensive review of our micro-inverter prototype. As a direct result of this investigation, GreenRay implemented numerous changes to the inverter design, including: circuit board geometry, trace design and layout, component layout, component technology and type, solder technology and method, potting technology and strategy. This study contributed significantly to our understanding of the challenges associated with achieving a high-reliability inverter. 
DE-FC36-07G017050

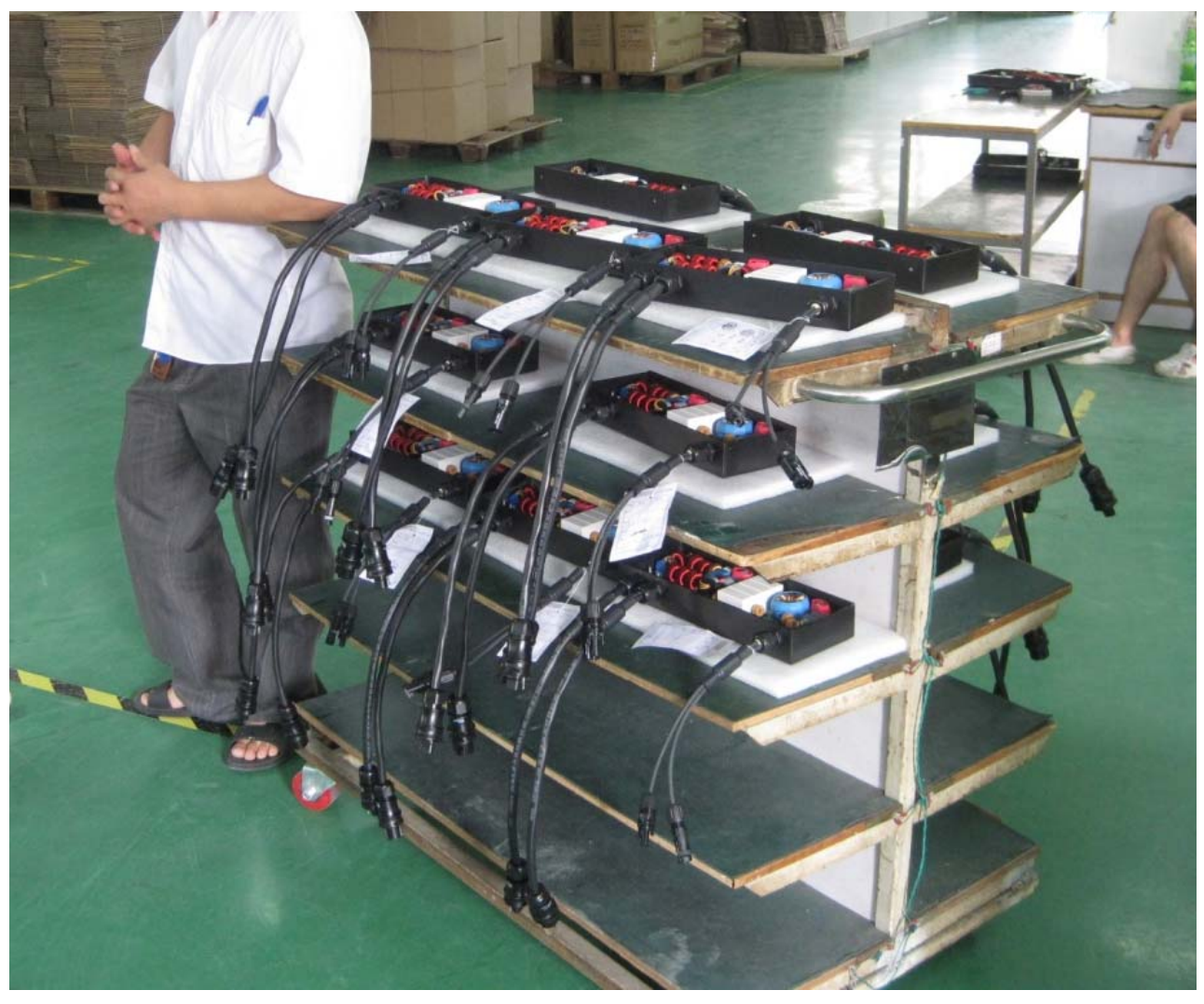

Multiple micro-inverters, post-inspection, on the factory floor 


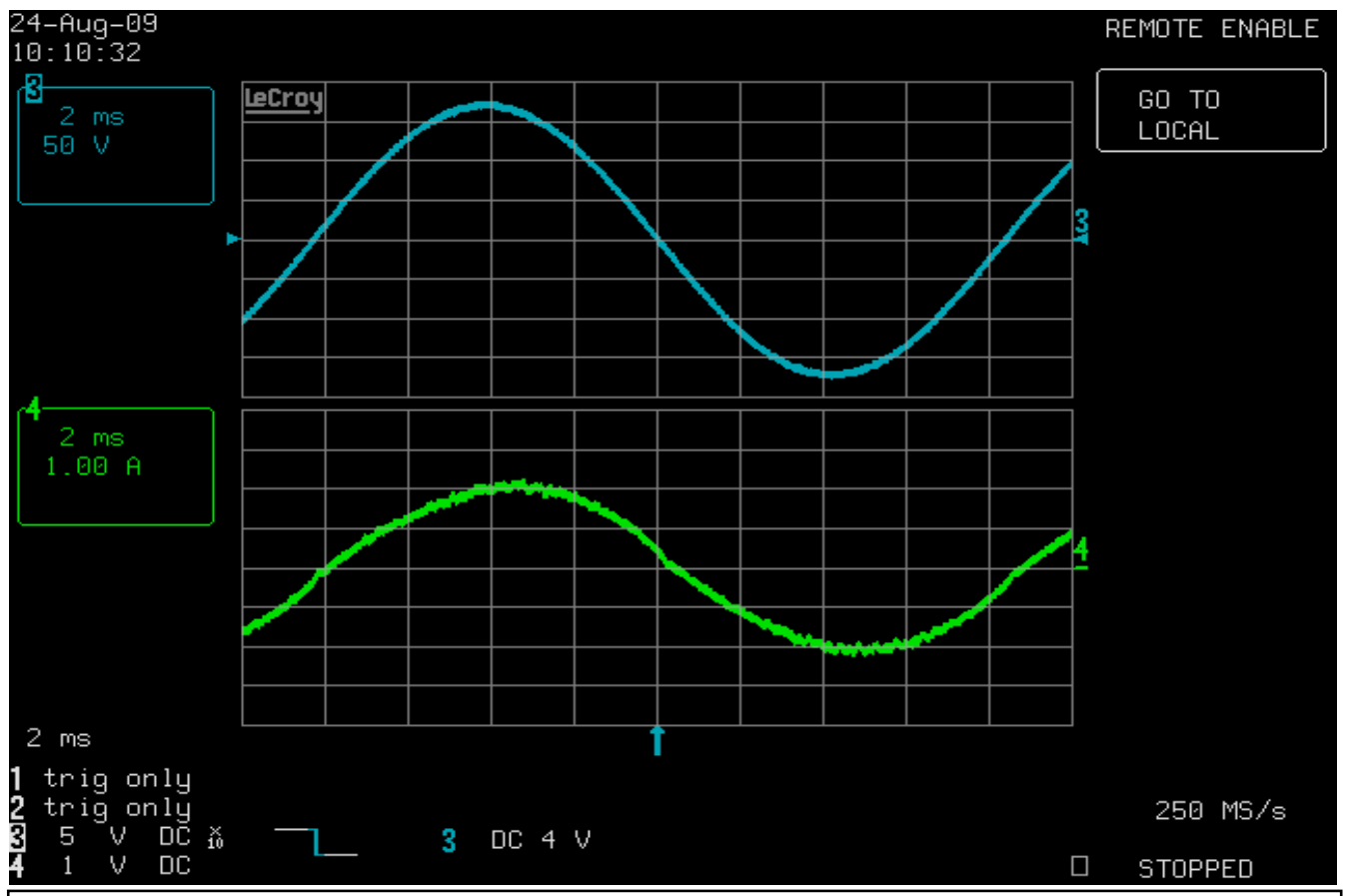

Scope trace of line voltage and synchronized inverter current waveform

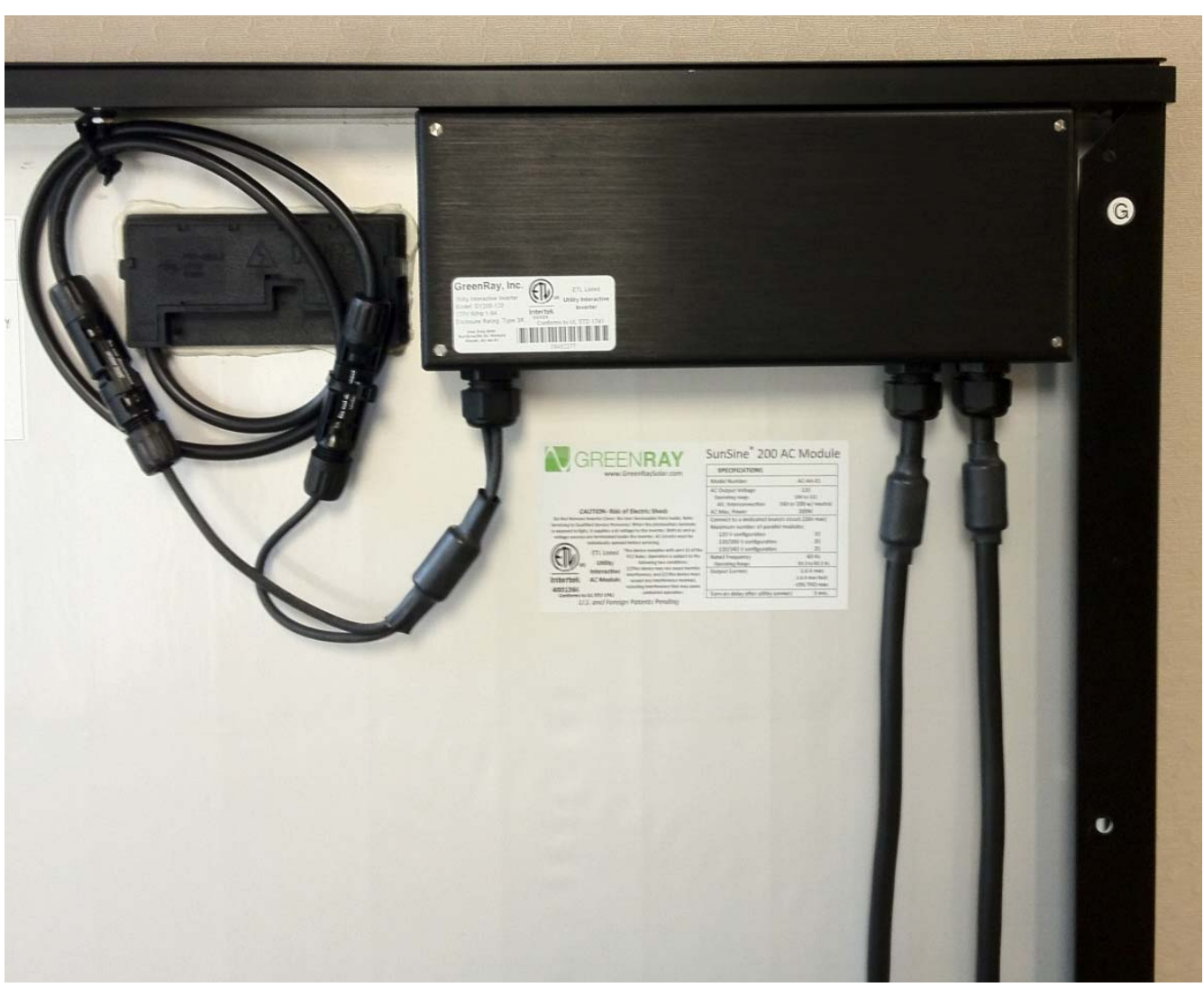

The GreenRay micro-inverter is attached to the module frame. 
DE-FC36-07G017050

Development of an AC Module System

GreenRay, Inc.

\section{Safety Certification}

Of necessity is the comprehensive testing of the AC Module for safety, by a nationally recognized testing laboratory; this process leading to certification or "listing". As the GreenRay AC Module development reached a state of readiness for the commencement of the safety certification evaluation, we prepared samples and conducted thorough in-house testing, to insure success in the subsequent testing at the laboratory.

Laboratory testing began in early 2010 and followed the requirements in the familiar UL 1741 standard - "Inverters, Converters, Controllers and Interconnection System Equipment for Use With Distributed Energy Resources". Evaluation and testing encompasses the following topics:

- Construction review

- Protection against risks of injury to persons

- Output power characteristics and utility compatibility

- Performance

- Rating

- Marking

- Manufacturing and Production Tests

Note that an AC Module is subjected to extra tests that are not required for a microinverter alone. Specifically, when a micro-inverter is factory integrated to a PV module, and designed to be a code-compliant AC Module, the integrated AC Module must undergo the Temperature Cycling and Humidity Cycling environmental stress sequences. These

UL tests conducted on GreenRay's AC Module that are not required for central inverters or micro-inverters:

Humidity-Freeze Cycling Test: the AC module is in a temperature-andhumidity-controlled chamber. Over 24 hours it makes one cycle between very high ambient temperature and humidity (85C and $85 \%$ relative humidity), where it dwells for 20 hours, and very cold conditions $(-40 \mathrm{C})$ where it dwells for a minimum of 30 minutes. A total of 10 cycles are conducted over a period of 10 days.

Temperature Cycling Test: the AC module is in a sealed temperaturecontrolled chamber. The temperature makes 4 cycles per day between $-40 \mathrm{C}$ and $+90 \mathrm{C}$, with a dwell time of 0.5 to 1.75 hours at both extremes. A total of 200 cycles are completed over a period of 50 days.

environmental stress tests are not required in the listing process for a micro-inverter alone, or a central inverter. 

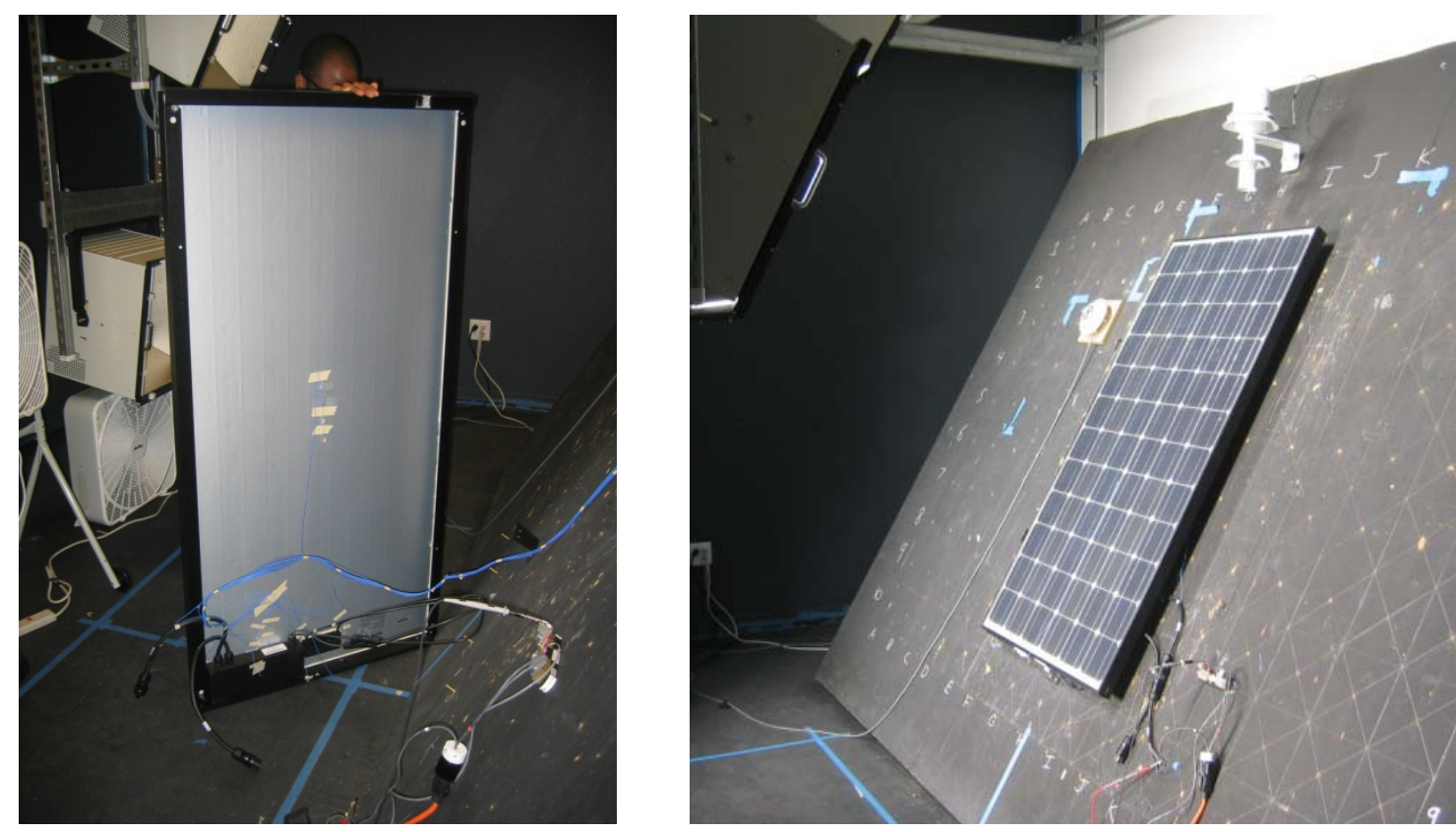

An AC Module is instrumented and undergoing temperature testing during safety certification.

Another test done as part of the safety certification process is the Temperature Test. The objective of the temperature test is to confirm that operating temperatures of all materials do not exceed their ratings. For this test, a $25 \mathrm{C}$ ambient temperature is maintained by an aircirculation system in the test chamber, the plane-of-array (POA) irradiance on the module surface is $1,100 \mathrm{~W} / \mathrm{m}^{2}(10 \%$ higher than nominal peak sunlight conditions used for rating of PV modules, which is $1,000 \mathrm{~W} / \mathrm{m}^{2}$. Thermocouples were installed in 8 locations under and around the micro-inverter and on the module back surface in various locations. The inverter was operated at its full power until all temperatures reasonably stabilized, which was approximately 14 hours. The results showed that all temperatures were within bounds and no temperature issues existed for the AC Module.

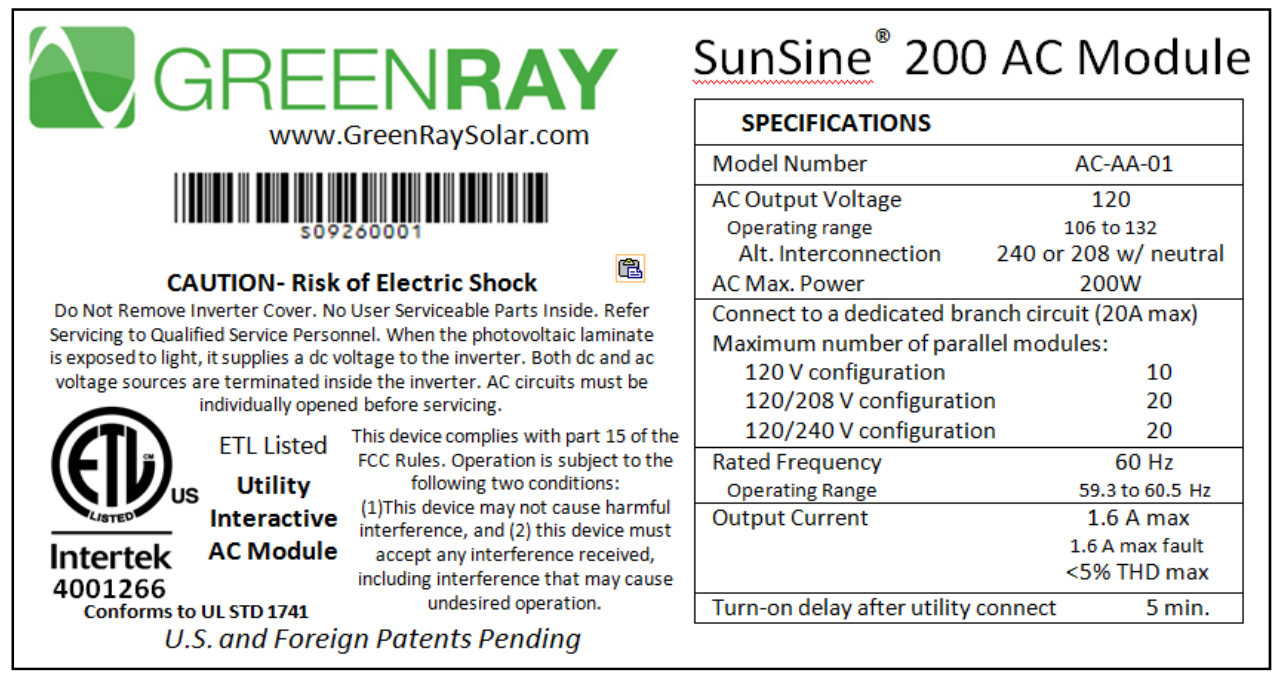

Safety Certification was completed in the summer of 2010. 


\section{Thermal Modeling}

One challenge faced with integrating an inverter and a PV module is to understand the impact that the inverter losses will have on the PV module's operating temperature. To investigate this early in our development, GreenRay established a testbed and monitored several PV modules mounted on a residential-type roof structure for several months. One PV module in this experiment was equipped with a faux inverter that simulated the energy losses of an actual micro-inverter. From the accumulated data in this experiment, a model was created and tuned to predict the measured performance with reasonable accuracy. The model then was exercised over a wide range of simulated environmental conditions to investigate the impact of the micro-inverter on the temperature of the module. A typical result is shown in the figures below.
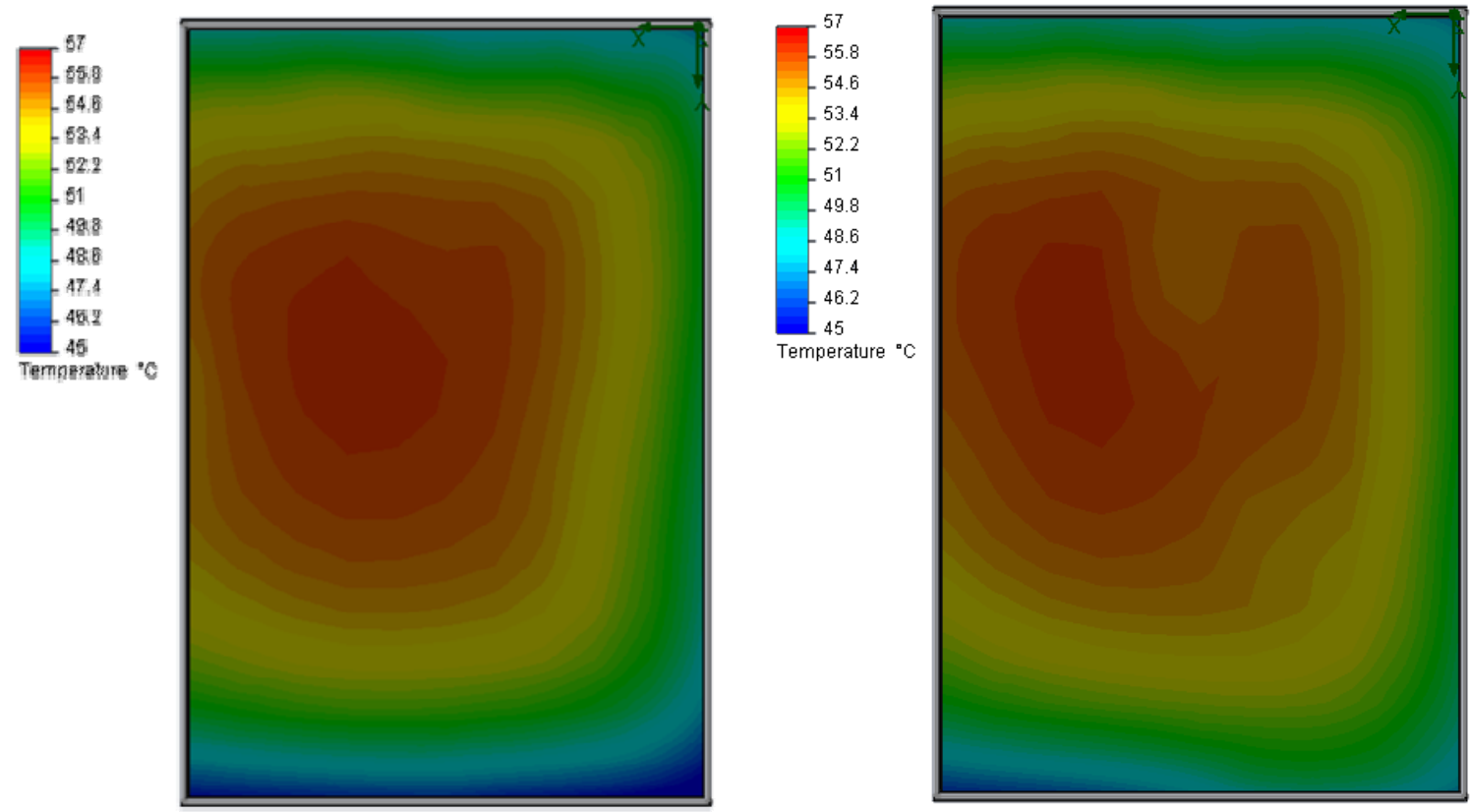

CFD modeling of tilted PV modules in full sunlight, no wind, and 25C ambient air temperature. Module on the right has a heat-dissipating micro-inverter, frame-attached in the lower right corner region. A slight increase in cell temperatures can be seen there, but temperatures remain well below the hottest cells in the module. 
DE-FC36-07G017050

Development of an AC Module System

GreenRay, Inc.

\section{Testing}

In our mission to create a differentiated high-reliability micro-inverter and fully-integrated AC Module, GreenRay undertook a broad range of aggressive stress testing and analysis, in an effort to unearth any weaknesses in the design. Specific stress tests included the following:

\section{High Temperature Test}

One branch of our testing is aimed at accelerated aging, that is, a finite-duration laboratory sequence that can bring about in a matter of months any life-ending phenomena that would otherwise be revealed only after many years in the field. Ideally such a laboratory test can establish a correlation between test time before failure and years in actual field use, and thereby be a credible indicator of the product's useful lifetime. Such a test protocol was used and published in the late 1990s in the Netherlands ${ }^{1}$ and it specifically targets micro-inverters and assessment of their useful lifetime.

From the referenced document:

This test is performed to determine the lifetime of the electronic components of the inverter. For this purpose the ambient temperature of the inverter is increased above the normal operating temperature. Normal aging processes will be accelerated. When the normal operating temperature is $T_{1}$ and the test is performed at inverter temperature $T_{2}$, it is assumed that the aging process is accelerated by a factor $A$, where $A$ is given by the Arrhenius relation:

$$
\begin{aligned}
& A=\exp \left\{-\frac{E a}{n K}\left(\frac{1}{T 2}-\frac{1}{T 1}\right)\right\} \quad \text { where }, \\
& \left.\frac{E a}{n}=\text { the activation energy (0.6 ev assumed }\right) \\
& K=\text { Boltzmann constant }\left(1.3806503 \times 10^{-23} \mathrm{~m}^{2} \mathrm{~kg} \mathrm{~s}^{-2} \mathrm{~K}^{-1}\right)
\end{aligned}
$$

Assuming 12 hours of daily operation under normal operating conditions, 2,000 hours at $85^{\circ} \mathrm{C}$ would equal an aging at $25^{\circ} \mathrm{C}$ during twenty years. The purpose of the test is to make an estimate of the effective activation energy of the AC inverter.

GreenRay conducted the high temperature test on its inverter following the procedures in the referenced paper, which requires maintaining the inverter in an ambient temperature of $75 \mathrm{C}$ and operating the inverter at $80 \%$ of full power continuously. The procedure specifies a nominal test period of 2,000 hours at these conditions, which would demonstrate a 20-year useful life in the climate of the Netherlands. GreenRay's inverter operated in this test for more than 10,000 hours without interruption and without failure of any type. This period of time-in-test equates to $60+$ years in a Phoenix climate, and $150+$ years in a Boston climate.

\footnotetext{
${ }^{1}$ Reliability Testing of AC-Module Inverters" by C.W.G. Verhoeve, C.F.A. Frumau, E. de Held and W.C. Sinke, Netherlands Energy Research Foundation ECN
} 


\section{Seasonal Temperature Cycling}

When operating in the field, the internal temperature of a micro-inverter undergoes a daily cycle that in the extreme could involve a swing of $75 \mathrm{C}$ or more between off-time at night and high-power operation during the hottest time of day. To assess the impact of repeated cycling, GreenRay devised an accelerated Seasonal Temperature Cycling test sequence. In this test the temperature of the inverter is cycled from a low of $-30 \mathrm{C}$ to a high of $+60 \mathrm{C}--$ a $90 \mathrm{C}$ temperature swing -- making one full temperature cycle each 24-hour period. The inverter operates at full power for two minute intervals at a 50\% duty cycle. During a 24-hour period this results in 365 "micro-days" (4-minute-long "day", with 2 minutes of full-power operation and 2 minutes of transition or off-time), or one "micro-year". In this way the inverter sees start-up, full-power operation and shut-down over a very wide range of temperature conditions and cycles its components more than 20,000 times. The GreenRay inverter completed 1,400 hours, or 60 "micro-years" of Seasonal Temperature Cycling with no failures.

\section{IEC 61215 Damp Heat Test}

The Damp Heat Test is designed to stress a PV module in an environmental soak at $85 \mathrm{C}$ with $85 \%$ relative humidity for 1,000 hours. A hi-pot test is performed before and after the soak to see if insulation systems have been compromised. The damp heat test is part of IEC 61215, an international test standard for crystalline modules. The damp heat test is not currently required in the U.S., and is not included in the UL1703 standard that guides module safety certification testing in the U.S. Also the damp heat test is not intended for inverters, nor required by any agency for inverters; it applies only to PV modules. Nonetheless, as an extreme environmental stress test, it is an excellent test for a micro-inverter. GreenRay contracted with a third party laboratory to conduct the damp heat test on three micro-inverters. The three units were operated and hi-pot tested before the soak, and again after the 1,000 hours at $85 \mathrm{C}$ and $85 \% \mathrm{RH}$. All units passed and suffered no significant degradation of insulation systems.

\section{UL1703 Humidity Freeze Cycling and Temperature Cycling}

Testing of the GreenRay micro-inverter went beyond what is required for standard central inverters or micro-inverters, because GreenRay's inverter is part of an AC module and that introduces additional tests. Specifically, the GreenRay micro-inverter underwent two accelerated aging environmental conditioning sequences, that are borrowed from the UL 1703 standard for the testing of PV modules: Humidity-Freeze Cycling and Temperature Cycling. These tests are described below. Following these environmental conditioning sequences, the inverter is subjected to a hi-pot test that checks for changes to the isolation between electrically-live parts (such as conductors carrying current) and de-energized metallic parts (such as the PV module's frame). In both tests, the units performed without failure.

Humidity-Freeze Cycling Test: the AC module is in a temperature-andhumidity-controlled chamber. Over 24 hours it makes one cycle between high ambient temperature and humidity ( $85 \mathrm{C}$ and $85 \%$ relative humidity), 
where it dwells for 20 hours, and very cold conditions (-40C) where it dwells for a minimum of 30 minutes. A total of 10 cycles are conducted over a period of 10 days.

Temperature Cycling Test: the AC module is in a sealed temperaturecontrolled chamber. The temperature makes 4 cycles per day between $40 \mathrm{C}$ and $+90 \mathrm{C}$, with a dwell time of 0.5 to 1.75 hours at both extremes. A total of 200 cycles are completed over a period of $\sim 50$ days.

\section{FCC Certification}

Products intended for installation on dwellings and commercial buildings must comply with the limits on radiated and conducted emissions as defined by the FCC. GreenRay's AC Module was tested in January 2010 and received its certificate of compliance with FCC Part 15, Subpart B that month.

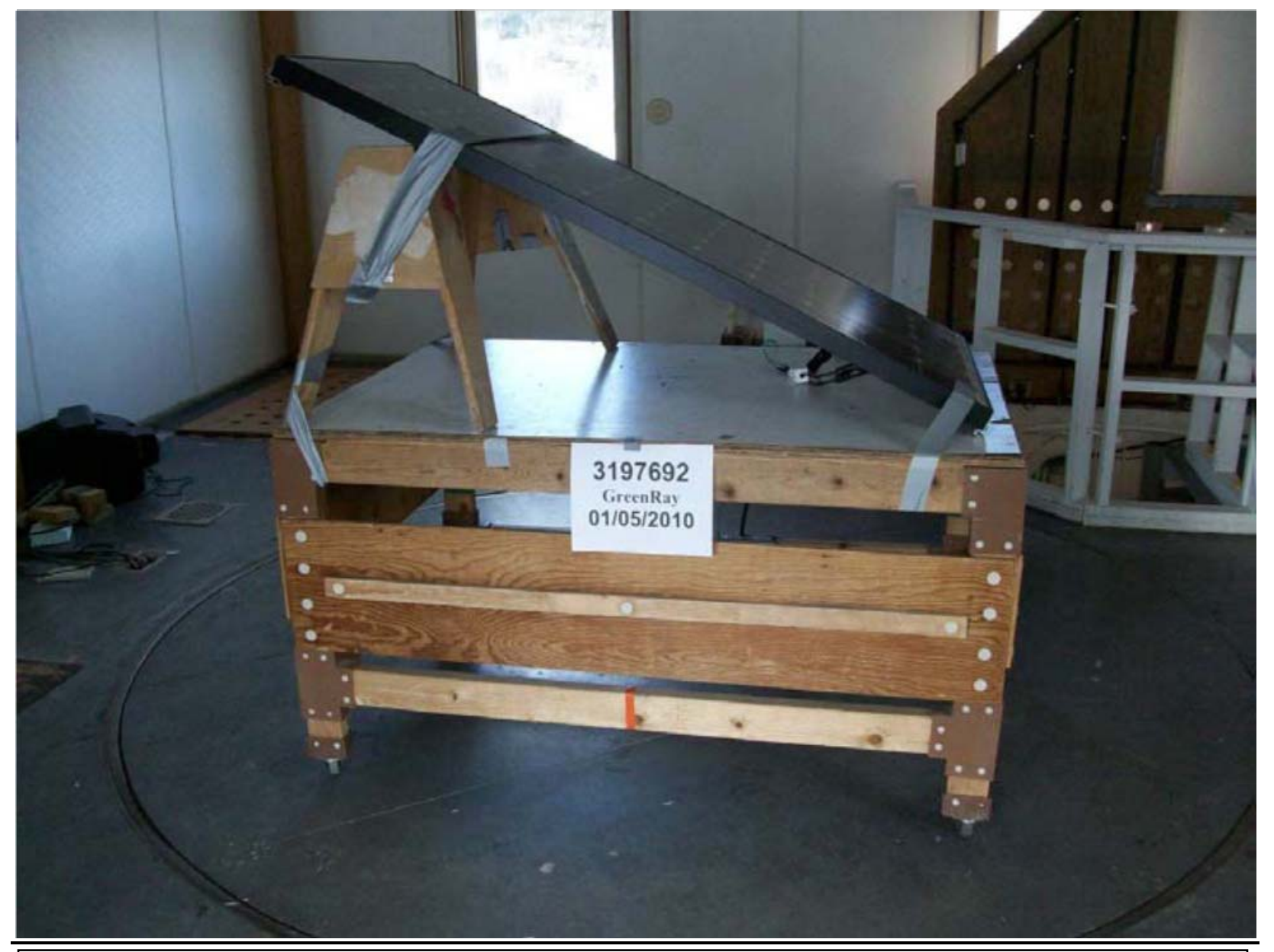

The GreenRay AC Module in the chamber for the FCC Class B radiated and conducted emissions testing (also known as the duct tape and sawhorse test). 


\section{In-House HALT Testing}

Highly-Accelerated Lifetime Testing is a sequence where a unit under test is stressed with the intent of determining the point at which the unit will fail.

For GreenRay's in-house testing, a sample micro-inverter was instrumented and placed in a temperature-controlled chamber. The unit's power was ramped slowly up to full power and operated for several hours at a fixed ambient temperature until all temperatures were reasonably stable. Testing started at an ambient temperature of $25 \mathrm{C}$ and incremented up in $5 \mathrm{C}$ steps. Over a period of two weeks testing continued, taking data and making observations of internal device temperatures at each step. The AC output waveform was also the carefully observed and recorded. When ambient temperature was set at 120C, the first failure of an internal component was observed.
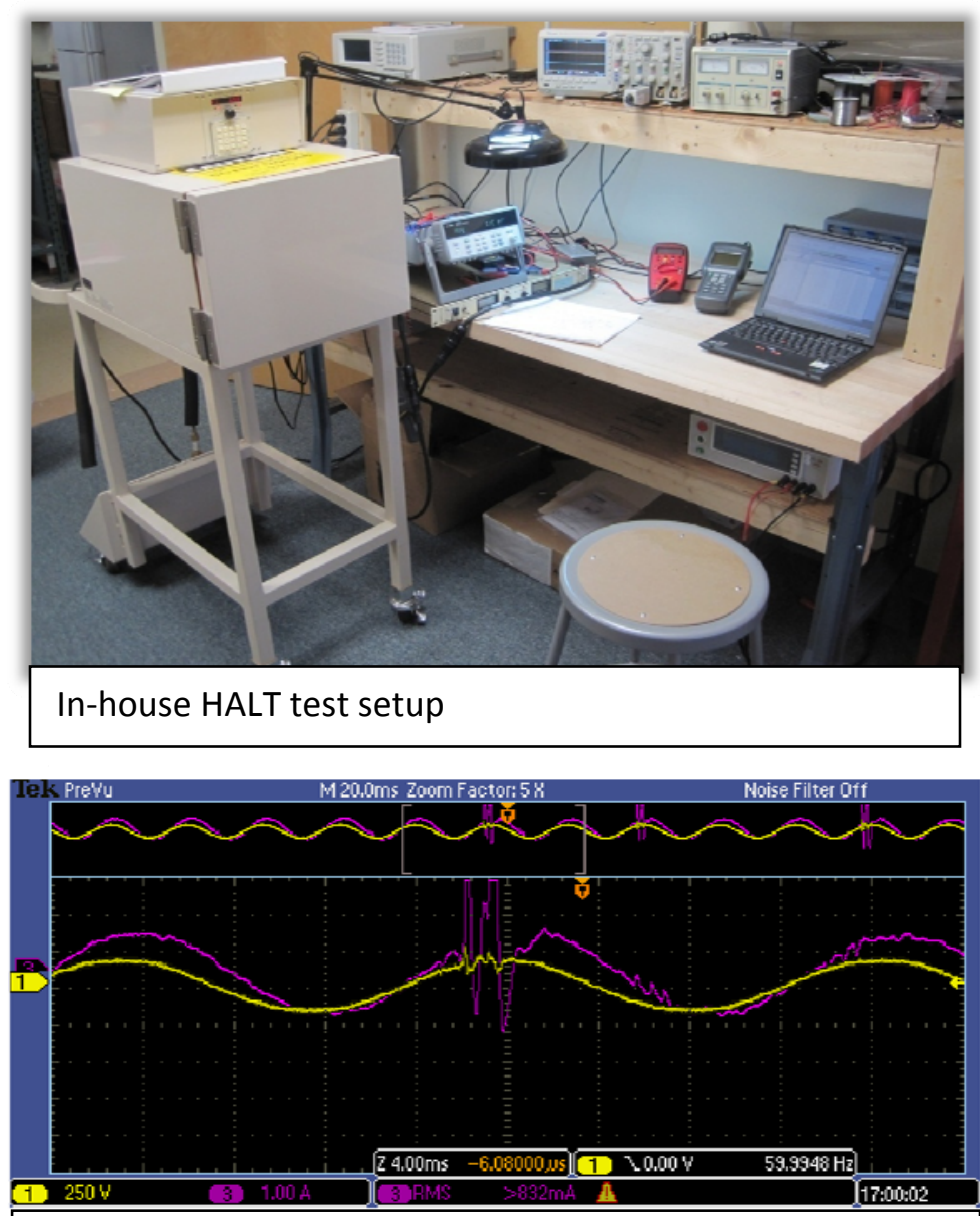

Waveform shows distortion when the point of device limit was reached at the $120 \mathrm{C}$ ambient condition.

These results demonstrated the GreenRay micro-inverter's survival to extreme temperature, far exceeding any specifications. This further validated the design margins and component derating strategy used, and the achievement of a robust design. 


\section{Predictive Analysis}

Predictive analysis using software tools such as Telcordia SR332 or MIL-STD-217F is useful in the design process to compare components and improve a product's design. In the analysis of MTBF, the goal is to assess the rate at which micro-inverters will fail during their useful life. For example, assume production of 10,000 micro-inverters and all of them begin operating in the same year. Ignoring the following years' production, further assume that those 10,000 microinverters are watched closely over the next 30 years. As each year goes by, what percentage of micro-inverters should be expected to fail in any given year? Intuitively, in the first months or year some initial failures would be expected; in year 28 more failures would be expected as the product nears the end of its lifetime. In between, the failures occurring should be random and at a low and stable rate. That middle period is the "useful life" of the product -- between the initial failures and end-of-life failures.

The well-known bathtub curve illustrates this and consists of three periods: an infant mortality period with a decreasing failure rate, followed by the useful life period with a low, relatively constant failure rate, and concluding with a wear-out period that exhibits an increasing failure rate. MTBF is not a predictor of the length of the useful life, but is simply a statistical measure of how reliable a product is during its useful life.

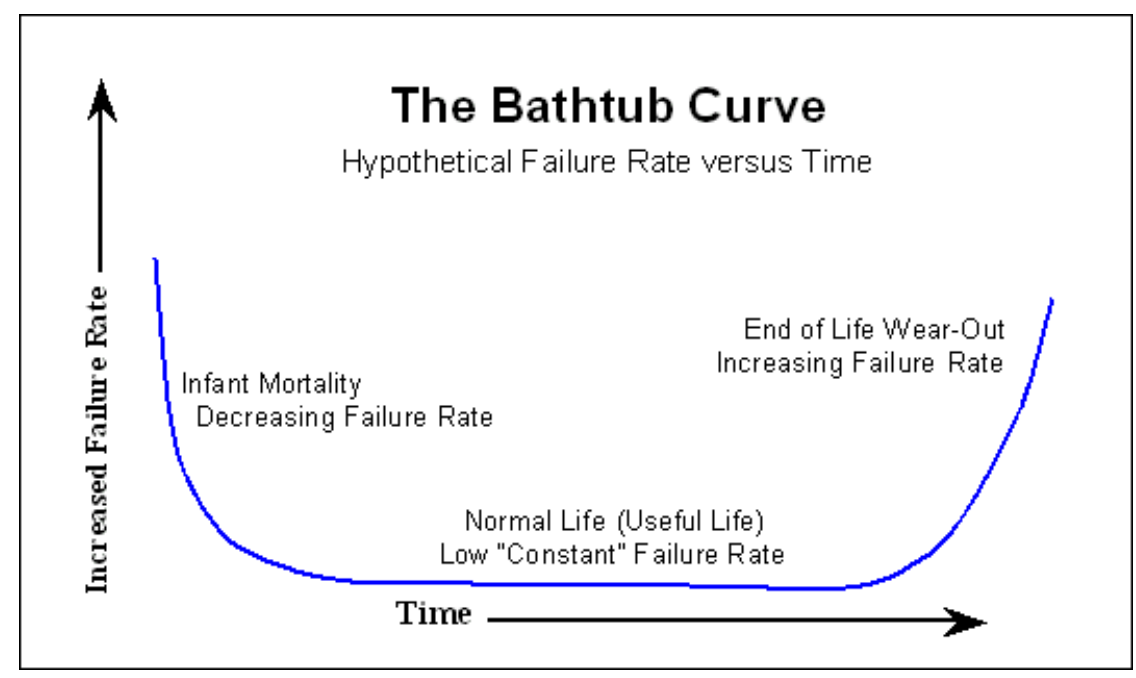


As noted, during the useful life of a product, failures occur randomly but at a constant average rate. Mathematically this suggests a distribution of events that is exponential. In statistics an exponential distribution arises naturally when modeling the time between independent events that happen at a constant rate. The amount of change in your pocket, and the life of a car battery also exhibit an exponential distribution. An exponential distribution is a type of probability distribution and takes the form:

[1] $f(\mathrm{t})=\lambda \mathrm{e}^{-\lambda \mathrm{t}} \quad$ (probability density function),

[2] $\quad F(t)=1-e^{-\lambda t}$ (cumulative probability distribution function)

[3] $\quad \mathrm{MTBF}=\frac{1}{\lambda} \quad$ (mean time between failures)

From these,

$$
\begin{array}{ll}
\text { [4] } & \mathrm{F}(\mathrm{t})=1-e^{-\frac{t}{M T B F}} \\
\text { [5] } & \mathrm{MTBF}=-\frac{t}{\ln (1-F(t))}
\end{array}
$$

What then does the MTBF actually mean? The MTBF is often confused with useful life, and the two are not the same. For example, assume a goal to limit the total number of failures of a product population to $10 \%$ over a 20 -year useful lifetime. What is the MTBF associated with those statistics?

$$
\begin{aligned}
& t=20 \text { years } \\
& F(t)=0.10\{10 \% \text { fail in time } t\} \\
& M T B F=-\frac{20}{\ln (1-0.10)}=190 \text { years! }
\end{aligned}
$$

GreenRay contracted Relex (www.relex.com), an engineering firm that performs reliability analyses for aerospace and other industries, to conduct the predictive analysis of its microinverter. Relex used the Telcordia - SR332 standard which originally comes from the telecommunications industry. This standard is the most appropriate for small power electronic devices working in the outdoor environment.

Relex's analysis predicts GreenRay's inverter to have an MTBF of 500 years. MTBF is not a predictor of useful lifetime but is a statistical measure relating to reliability. 


\section{Assembly and Manufacture}

GreenRay receives standard 200 Watt PV modules from Sanyo, and the GreenRay microinverter from our contract manufacturer partner. On site in our facility the final assembly of the AC module takes place.

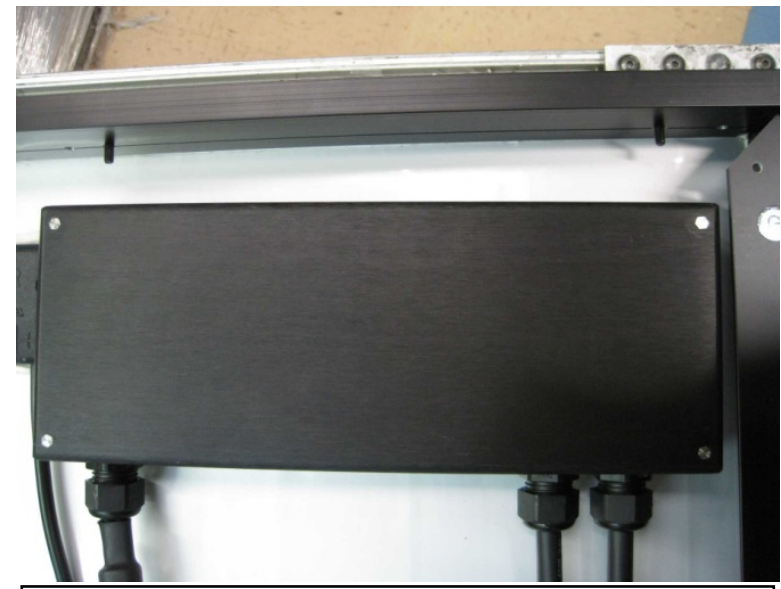

Inverter secures to module frame using two fasteners

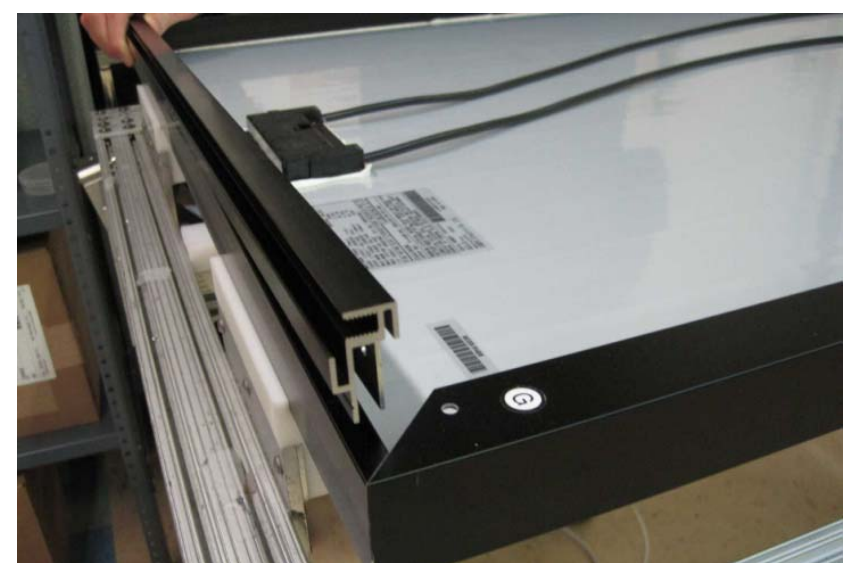

Frame modifier attaches to standard module frame.

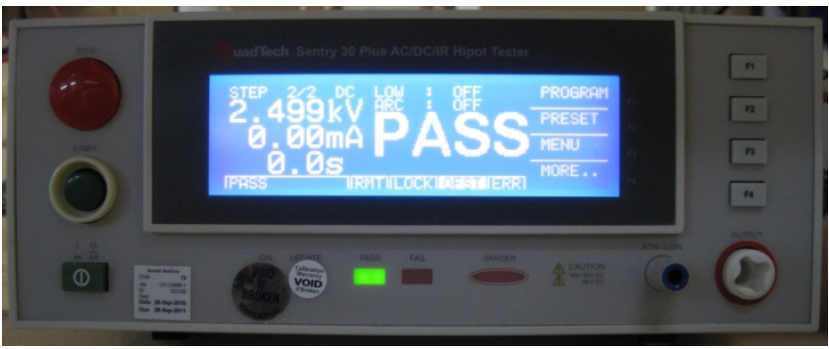

The finished AC Module is hi-pot tested, then labels are applied.

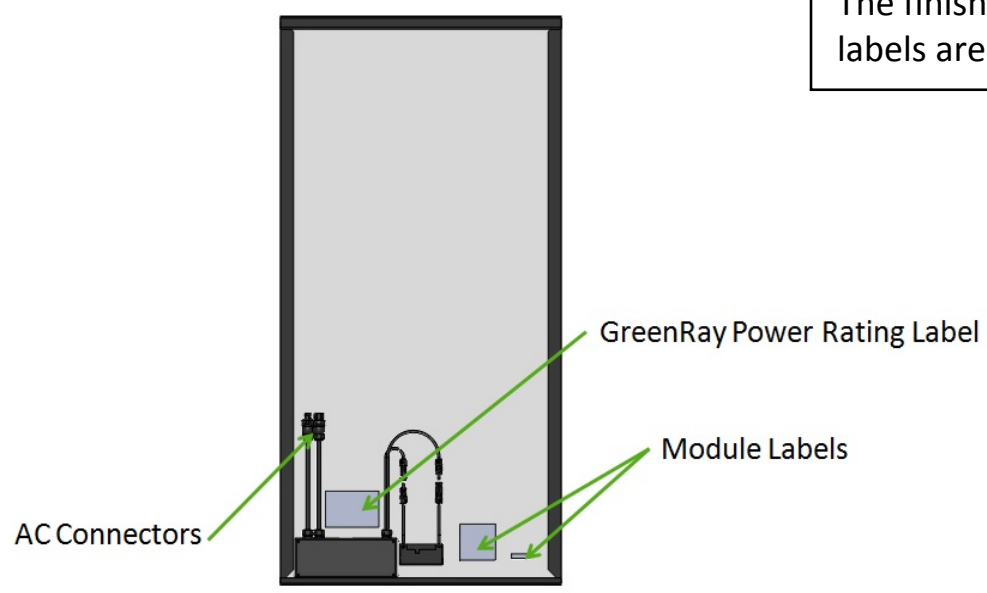

Depiction of the assembled AC Module

Page 25 of 43 


\section{Residential Mounting}

As a companion to the AC Module, GreenRay developed a residential mounting system that eliminates standard racking. The objective was to reduce cost through reduction in materials and at the same time reduce time on the roof for an installation. The GreenRay approach was to incorporate features in the module frame that would facilitate and simplify mounting, and require only mounting feet to support the panels. Complete replacement of the module's frame was not feasible during our pilot phase, so instead we created an add-on modification to the standard module frame, in order to demonstrate the concept effectively. The frame with its added elements provides a feature to accept the companion mounting feet at any position along its east-west dimension.

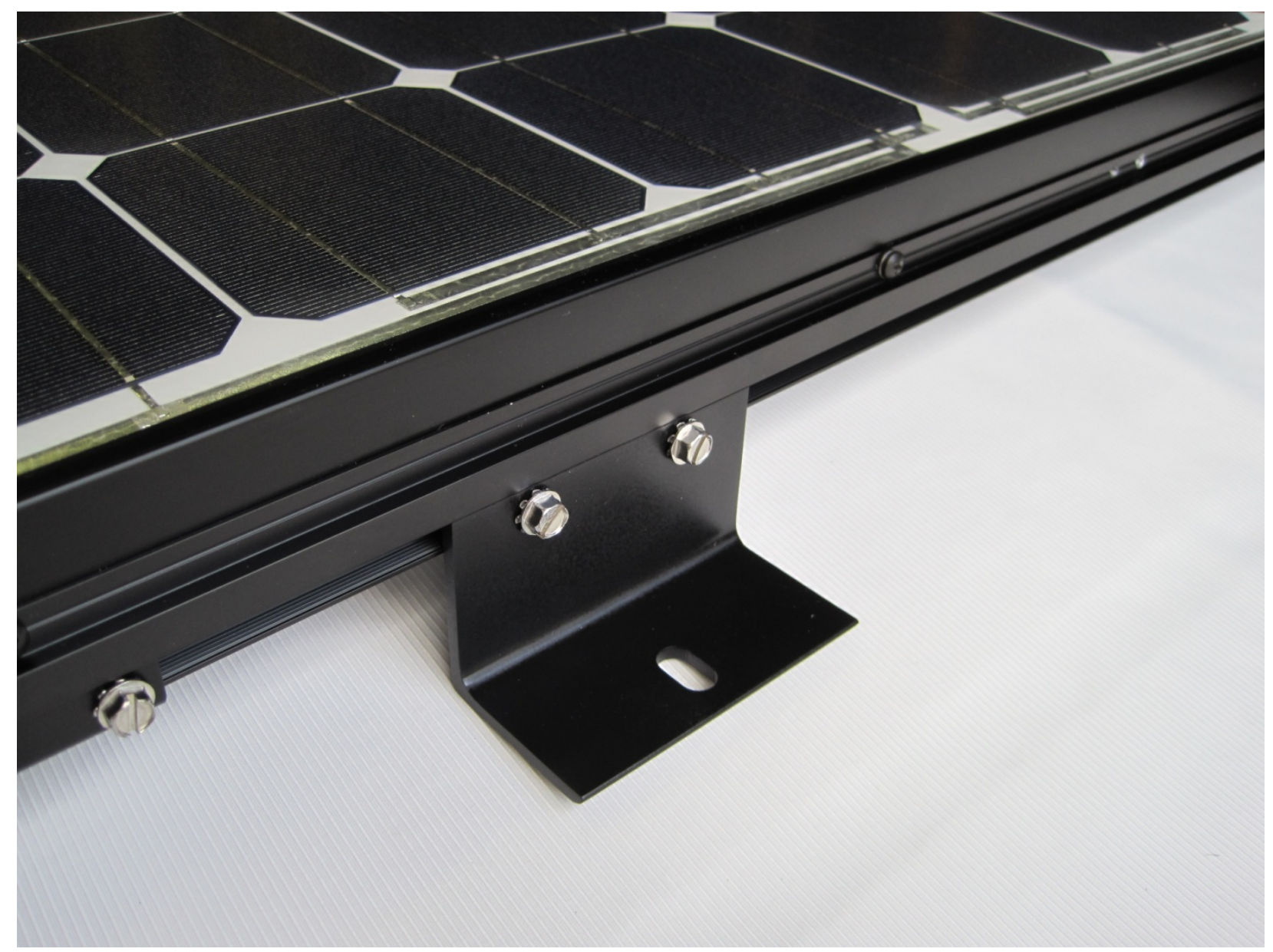

Reaction to the mounting system was mixed, at first, as it represents a dramatic shift in the way modules are traditionally installed. However, after gaining further experience with multiple installations and encountering different roof situations, the advantages became clear. Berkshire Photovoltaic Systems (Adams, MA) ultimately found that their installation time on the roof was reduced up to $25 \%$ with the GreenRay mounting system. 


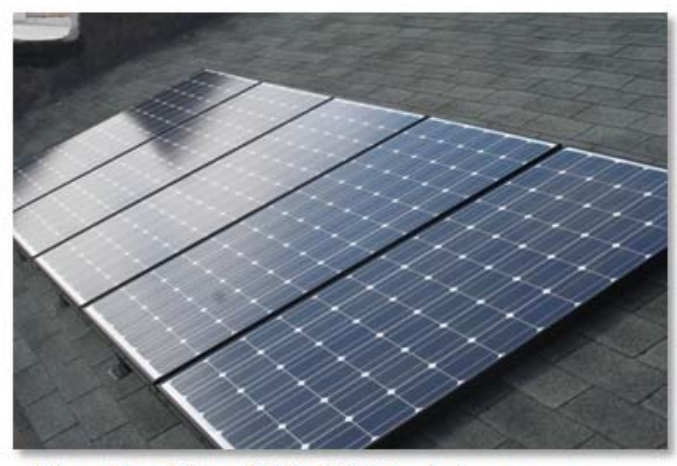

Five SunSine 200 AC Modules on a wavy roof in $\mathrm{NJ}$ (October 2009)

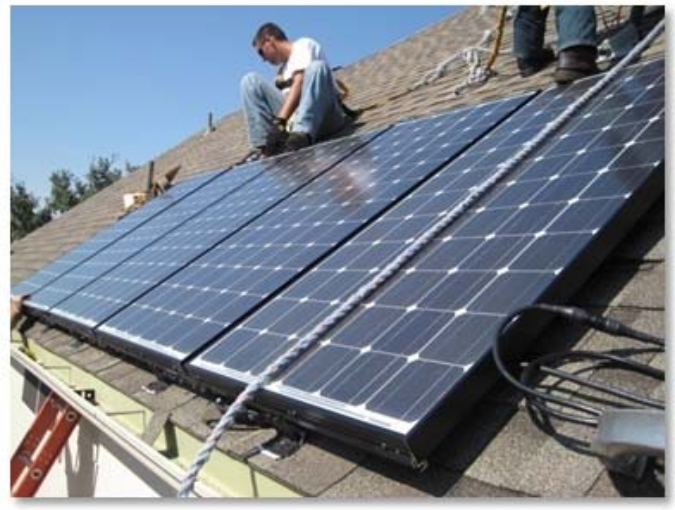

Five SunSine 200 AC Modules on a home in Houston, TX (October 2009)

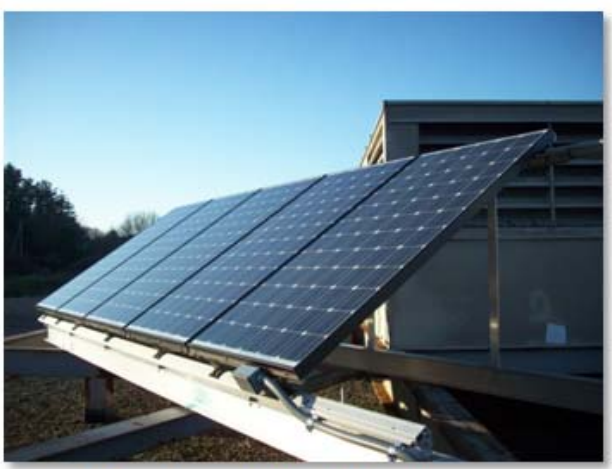

Five SunSine 200 AC Modules on National Grid's roof in Northboro, MA (November 2009)

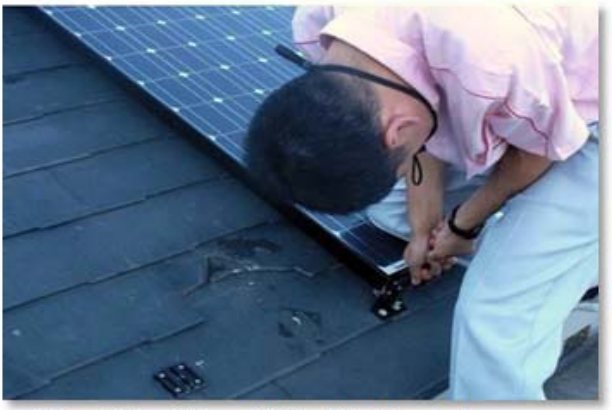

Two SunSine 200 AC Modules on a test roof in Osaka, Japan (August 2009)

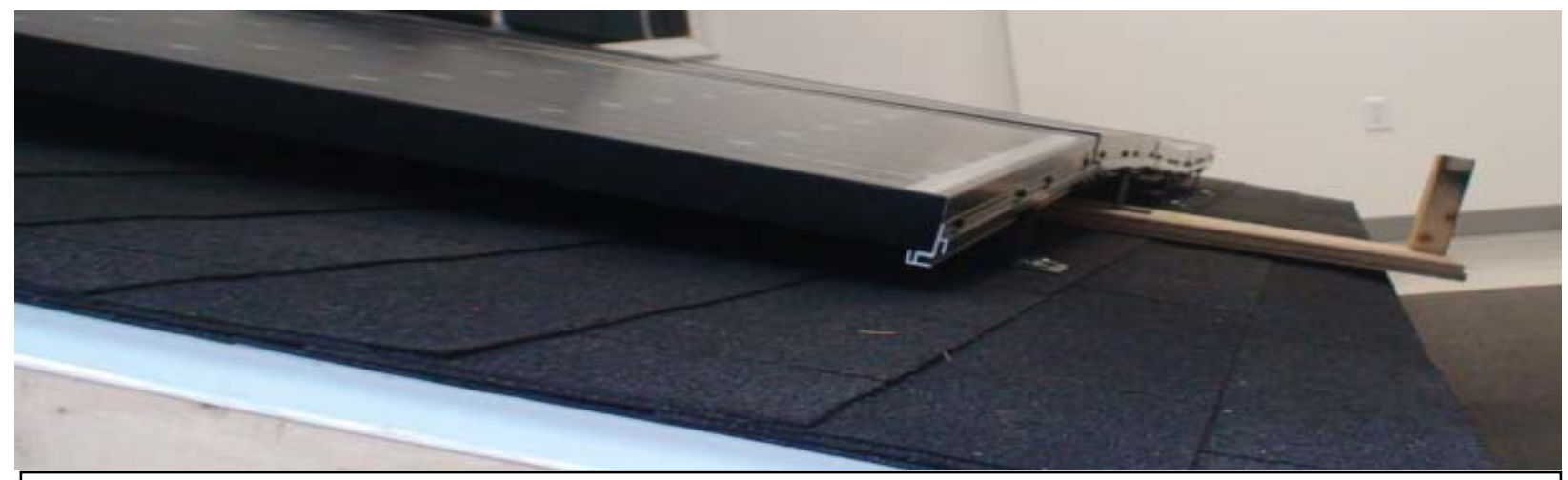

Non-planarity of roofs is not uncommon and such conditions were factored into the mounting system design and testing.

The mounting system and AC Module were tested in numerous early installations, to gauge customer acceptance, and get feedback on the installation process and hardware components. In-house all manner of expected roof conditions were evaluated and factored into the design of the mounting system, including non-planar (wavy) roofs. 
DE-FC36-07GO17050

Development of an AC Module System

GreenRay, Inc.

\begin{tabular}{|c|c|c|c|c|c|c|c|c|c|c|c|c|c|c|}
\hline \multirow{2}{*}{\multicolumn{15}{|c|}{$\begin{array}{l}\text { Bnsic Wind Speed c } 100 \mathrm{mph} \text { in Hurricane-Prone Regions or c } \\
\text { Mast }\end{array}$}} \\
\hline \multirow{6}{*}{$\begin{array}{l}\text { Greurd } \\
\text { Snow } \\
\text { togd }\end{array}$} & \multicolumn{13}{|c|}{ 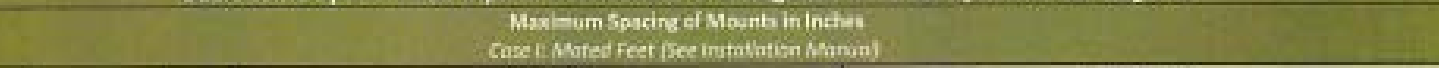 } & \\
\hline & \multirow{4}{*}{ Most Slope } & \multirow{5}{*}{ Foce } & \multirow{2}{*}{\multicolumn{6}{|c|}{ 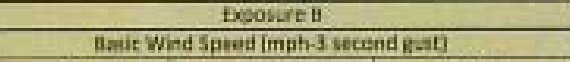 }} & \multicolumn{6}{|c|}{ Expmare C } \\
\hline & & & & & & & & & \multicolumn{6}{|c|}{ Basic Wha Sseed imph-3 second zust) } \\
\hline & & & \multicolumn{2}{|c|}{ BS } & \multicolumn{2}{|c|}{90} & & & & & & & & \\
\hline & & & \multicolumn{6}{|c|}{ moum to al rafters or sitemese faften } & \multicolumn{6}{|c|}{ moumt to ol rafters or a teraste rafters } \\
\hline & seelifine & & $3 i$ & Nitrmat: & AI & atiemate & 4 & Akeirabe & $a$ & shemate & al & altematn & at & alimate \\
\hline \multirow{9}{*}{ 管 } & & 1 & es & 44 & as & 44 & 4a & 44 & 48 & 44 & 48 & 44 & 43 & 41 \\
\hline & 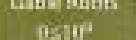 & 3 & 48 & 44 & 48 & 42 & 45 & 39 & 45 & 30 & 40 & 35 & 32 & 32 \\
\hline & & 3 & 43 & 37 & 38 & 35 & 30 & 30 & 30 & 30 & 27 & 27 & 21 & N/A \\
\hline & Gible or Hp & +1 & 48 & 44 & 48 & 44 & 48 & 4 & 48 & 44 & 48 & 42 & 48 & 39 \\
\hline & Hoes & 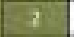 & 48 & 42 & 48 & 39 & 39 & 35 & 38 & 35 & 34 & 33 & 27 & 27 \\
\hline & $10^{2}<4=30^{2}$ & 3. & 48 & 42 & 48 & 39 & 31 & $n$ & 38 & 35 & 34 & 33 & 22 & N/A \\
\hline & & 1 & 48 & 42 & 48 & 40 & 49 & 37 & 48 & 37 & 48 & 35 & 28 & 12 \\
\hline & anperagen & 2 & 48 & 42 & 48 & 40 & 4 & 37 & 48 & 3Y & 41 & 35 & 45 & 32 \\
\hline & & 3. & 48 & 42 & 48 & 40 & 4 & 37 & 48 & 37 & 48 & 35 & 45 & 32 \\
\hline & & 1 & 48 & 38 & 48 & 38 & 4 & 38 & 48 & 38 & 48 & 38 & 48 & 38 \\
\hline & As in" & 2 & 48 & 38 & 48 & 38 & 45 & 38 & 45 & 38 & 40 & 35 & 32 & 12 \\
\hline & & 3 & 43 & 37 & 38 & 35 & 30 & 30 & 30 & 30 & 27 & 27 & 21 & $\mathrm{~N} / \mathrm{A}$ \\
\hline & Gather $\mathrm{Hp}$ & 2 & 48 & 38 & 48 & 38 & 43 & 38 & 48 & 38 & 48 & 37 & 45 & 35 \\
\hline a & Mosi & 2. & 48 & $3 a$ & 48 & 39 & 3 & 35 & 38 & 35 & 34 & 39 & 27 & 27 \\
\hline & $10^{\circ}<18=30^{\circ}$ & 3 & 48 & 38 & 48 & 39 & 31 & 31 & 38 & 35 & 34 & 33 & 22 & $\mathrm{~N} / \mathrm{A}$ \\
\hline & & 1 & 48 & 39 & 48 & 37 & $4 i$ & 35 & 48 & 35 & 43 & 34 & 48 & 31 \\
\hline & $30204045^{\circ}$ & 2 & 48 & 38 & 48 & 37 & 48 & 35 & 48 & 35 & 4 & 34 & 45 & 31 \\
\hline & & 3 & 48 & 38 & 49 & 37 & 48 & 35 & 48 & 35 & 43 & 34 & 45 & 31 \\
\hline & & 1 & 48 & 32 & 49 & 32 & 48 & 32 & 48 & 32 & 43 & 32 & 48 & 32 \\
\hline & osief & 2 & 48 & 32 & 49 & 32 & 45 & 32 & 45 & 32 & $\infty$ & $n 2$ & 32 & 32 \\
\hline & & 3 & 43 & 32 & sa & 32 & 30 & 30 & 30 & 30 & 27 & 27 & 21 & $\mathrm{~N} / \mathrm{A}$ \\
\hline & Geble or mp & 1 & $4 a$ & 32 & 48 & 32 & 48 & 32 & 48 & 32 & 4 & 32 & 48 & 31 \\
\hline g & Mouf & 2. & 48 & 32 & 48 & 32 & 39 & 32 & 38 & 32 & 34 & $n$ & 27 & 27 \\
\hline & $10<<\theta=30^{\circ}$ & 3 & 48 & 32 & $4 a$ & 32 & 31 & 31 & 38 & 32 & 34 & 32 & 22 & $\mathrm{~N} / \mathrm{A}$ \\
\hline & & 1 & 43 & 32 & 43 & 32 & 48 & 31 & 43 & 30 & 4 & $\$ 0$ & 48 & 28 \\
\hline & $30^{\circ}<10-15^{\circ}$ & 2 & 49 & 32 & 48 & 32 & 48 & 31 & 48 & 30 & 48 & 30 & 45 & 28 \\
\hline & & 3 & 48 & 32 & 43 & 32 & 48 & 31 & 43 & 30 & 48 & 30 & 45 & 28 \\
\hline & & 1 & 43 & 28 & 43 & 23 & 48 & 28 & 48 & 28 & 48 & 28 & 48 & 28 \\
\hline & $\begin{array}{l}\text { Gotie Anots } \\
\text { elice }\end{array}$ & 2 & 43 & 28 & 43 & 24 & is & 28 & 45 & 28 & $\infty$ & 28 & 32 & 28 \\
\hline & & 3 & 4 & 28 & 39 & 28 & 30 & 28 & 30 & 28 & 27 & 27 & 21 & $\mathrm{~N} / \mathrm{A}$ \\
\hline & Geble or itito & 1 & 43 & 28 & 43 & 23 & 48 & 28 & 43 & 28 & 48 & 28 & 48 & 27 \\
\hline 吾 & Boots & 2 & 48 & 28 & 49 & 28 & 39 & 28 & 38 & 28 & 34 & 28 & 27 & 27 \\
\hline & tofet -5 & $\equiv$ & 43 & 28 & 4 & 23 & $\pi$ & 28 & 39 & 20 & $3 t$ & 28 & 22 & N/A \\
\hline & & 1 & 4 & 29 & 43 & 29 & 48 & 28 & 43 & 28 & 48 & 27 & 48 & 26 \\
\hline & $30 t<0 \leq 65^{\circ}$ & 2 & 4 & 29 & 4 & 20 & 48 & 28 & 48 & $2 \mathrm{a}$ & 48 & 27 & 45 & 26 \\
\hline & & 3 & 43 & 29 & 43 & 29 & 48 & 28 & 43 & 28 & 45 & 27 & 45 & 26 \\
\hline & & 1 & $48^{*}$ & $25^{\circ}$ & $48^{*}$ & $25^{\circ}$ & $48^{*}$ & $25^{*}$ & $43^{*}$ & $25^{\circ}$ & $48^{\circ}$ & $25^{\circ}$ & $49^{\circ}$ & $25^{\circ}$ \\
\hline & $\begin{array}{c}\text { Gaved pots } \\
\text { ostip }\end{array}$ & 2 & $45^{\circ}$ & $25^{\circ}$ & $45^{*}$ & $25^{\circ}$ & $45^{\circ}$ & $25^{*}$ & $45^{\circ}$ & $25^{\circ}$ & $40^{\circ}$ & $25^{\circ}$ & $32^{\circ}$ & $25^{\circ}$ \\
\hline & & 3 & $43^{*}$ & $25^{\circ}$ & $35^{*}$ & $25^{\circ}$ & $30^{\circ}$ & $25^{*}$ & $30^{\circ}$ & $25 *$ & $27^{*}$ & $25^{\circ}$ & $21^{*}$ & $N / A$ \\
\hline & Cote or tilp & 1 & $48^{\circ}$ & $25^{\circ}$ & $45^{\circ}$ & $25^{\circ}$ & $4 \mathrm{a}^{\circ}$ & $25^{\circ}$ & $45^{\circ}$ & $25^{*}$ & $48^{\circ}$ & $25^{\circ}$ & $49^{\circ}$ & $25^{\circ}$ \\
\hline$\frac{2}{2}$ & Esots & 2 & $45^{\circ}$ & $25^{*}$ & $48^{\circ}$ & $25^{*}$ & $39^{*}$ & $\mathrm{z}^{*}$ & $38^{*}$ & $25^{*}$ & $34^{\circ}$ & $25^{\circ}$ & $27^{*}$ & $25^{*}$ \\
\hline & Mrceso & 3 & $45^{\circ}$ & $25^{\circ}$ & 45. & $25^{\circ}$ & $3 H^{*}$ & $25^{*}$ & $34^{*}$ & $25^{\circ}$ & $34^{\circ}$ & $25^{\circ}$ & $22^{*}$ & N/A \\
\hline & & 1 & 48 & 26 & 48 & 26 & 48 & 25 & 43 & 25 & 48 & 25 & 48 & 24 \\
\hline & $35 f=0255^{\circ}$ & 2 & 48 & 26 & as & 26 & 48 & 25 & 4 & 25 & 46 & 25 & 45 & 24 \\
\hline & & 3 & 48 & 26 & 48 & 26 & 48 & 25 & 43 & 25 & 45 & 25 & 45 & 24 \\
\hline & & 1 & $48^{\circ}$ & $\mathrm{N} / \mathrm{A}$ & $48^{\circ}$ & $\mathrm{N} / \mathrm{A}$ & $49^{\circ}$ & N/A & $48^{\circ}$ & $\mathrm{N} / \mathrm{A}$ & $48^{\circ}$ & $N / A$ & $48^{\circ}$ & $N / A$ \\
\hline & astit? & 2 & $4 \mathrm{E}^{\circ}$ & N/A & $48^{\circ}$ & $\mathrm{N} / \mathrm{A}$ & 45. & $\mathrm{N} / \mathrm{A}$ & $45^{*}$ & $N / A$ & $40^{*}$ & $N / / A$ & $32^{*}$ & N/A \\
\hline & & 3 & $43^{*}$ & $\mathrm{~N} / \mathrm{A}$ & $38^{\circ}$ & $\mathrm{N} / \mathrm{A}$ & $30^{*}$ & $\mathrm{~N} / \mathrm{A}$ & $30^{\circ}$ & $\mathrm{N} / \mathrm{A}$ & $27^{\circ}$ & $\mathrm{N} / \mathrm{A}$ & $21^{*}$ & $\mathrm{~N} / \mathrm{A}$ \\
\hline ex & pplie & th & & es & 1 & ts & 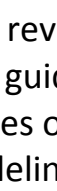 & $\mathrm{i} \epsilon$ & 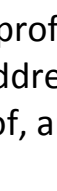 & 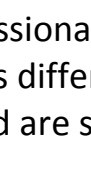 & $\mathrm{Cl}$ & o a & e. & eds, \\
\hline
\end{tabular}


DE-FC36-07GO17050

Development of an AC Module System

GreenRay, Inc.
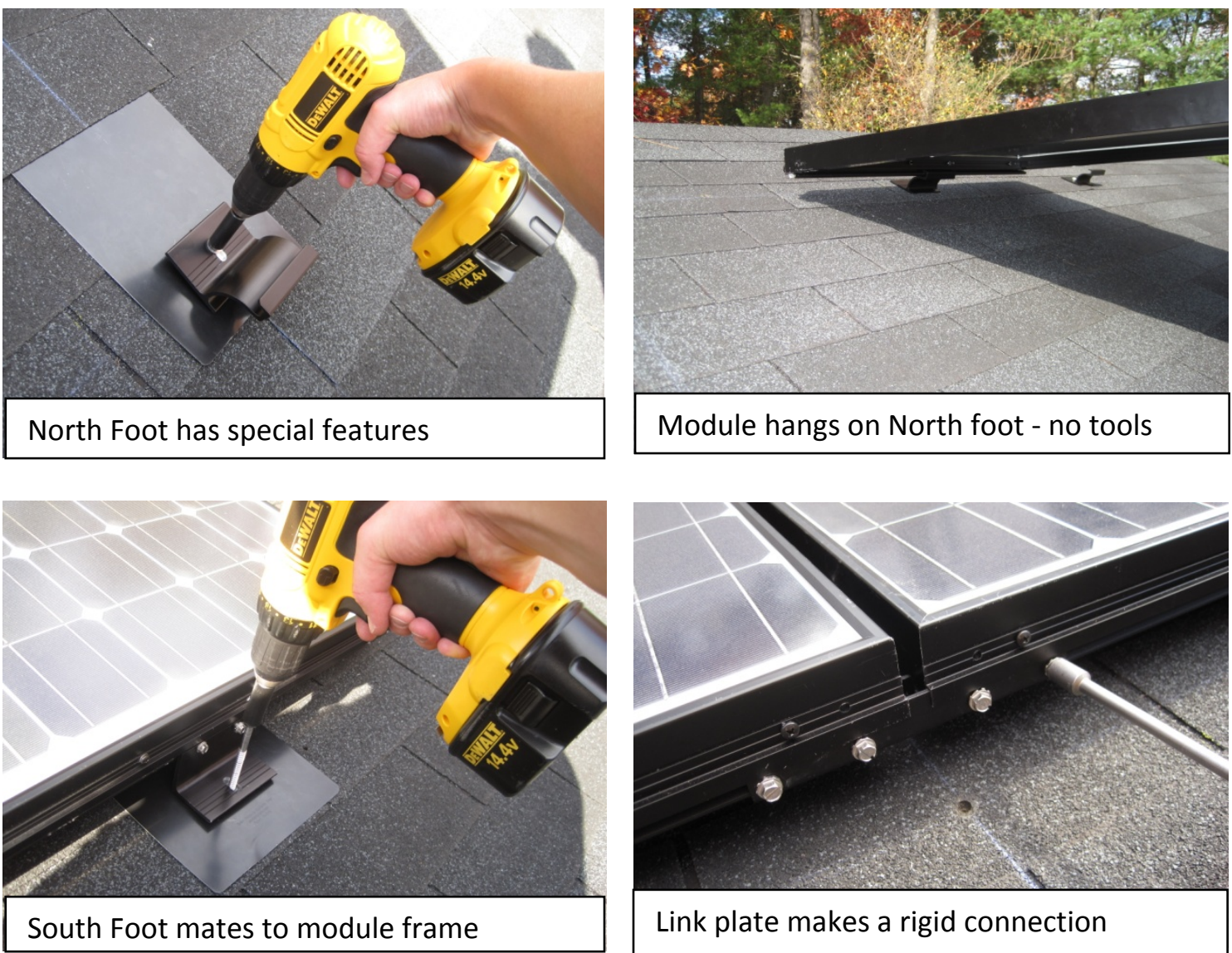

Link plate makes a rigid connection

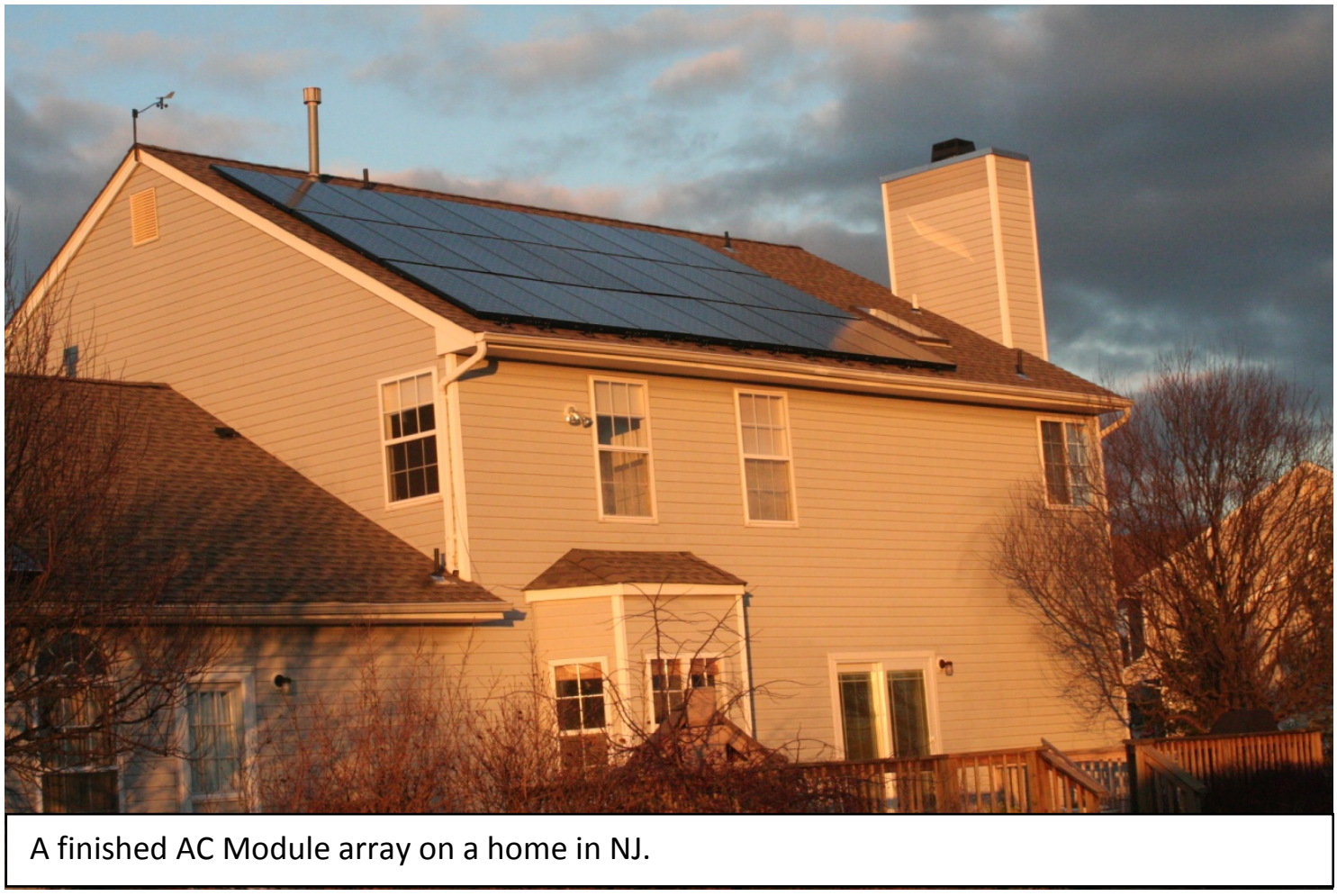

Page 29 of 43 


\section{Communications}

Module-level monitoring is a significant advantage of having an intelligent device -- the microinverter -- on-board the PV module. One of the inverter's responsibilities is to monitor continually the parameters on the PV module and also the grid. In addition it tracks its own internal temperature and operational status. GreenRay chose industry-standard powerline communications as the technology for transmitting the data from the micro-inverter to the outside world. Features of the monitoring and communications include the following:

Data Collection: The inverter monitors and records AC and DC current and voltage values and others, plus its internal temperature and its operational status.

Data Flow: Data flow is bi-directional, allowing performance and status information to flow out and requests to come in to the inverter via the powerline. An on-board powerline chip is responsible for all data $I O$.

Data Storage: Unlike any other inverter today, GreenRay's micro-inverter stores summary performance values on an internal chip for more than 20 years. In this way, if the data flow is ever interrupted, the data itself is not lost and in summary form can be retrieved from the inverter.

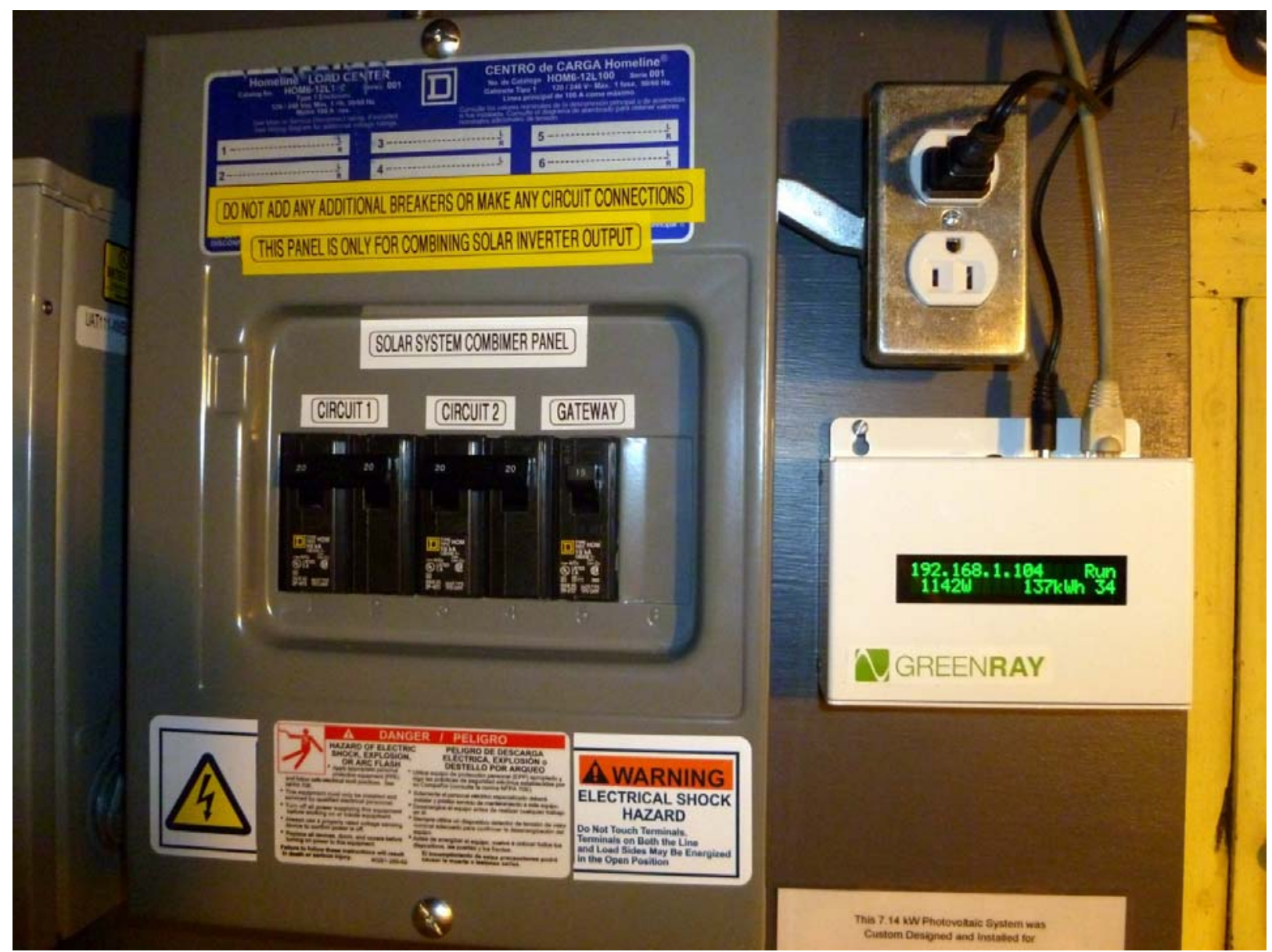

The GreenRay gateway displays key system information including the number of modules reporting and the total system power. 
GreenRay developed a gateway and designed a custom enclosure for the product. The gateway essentially plugs into any outlet in a home, senses the powerline communication from the AC modules, filters that signal and displays key information, such as the number of modules reporting, and the total system power. The gateway communicates to the internet in one of two ways: it has a port to connect an ethernet cable, and it also comes in a wireless version. Once connected to the web, the data is automatically uploaded to GreenRay's server for further data analysis and manipulation.

GreenRay further developed a website where system owners and installers can view system performance and history at any time. The dashboard underwent numerous iterations and one lesson learned is that this window into the system is the single most important feature of the PV system to most of the system owners. 
DE-FC36-07G017050

Development of an AC Module System

GreenRay, Inc.

\begin{tabular}{|c|c|c|c|}
\hline \multicolumn{3}{|c|}{ Bivas Residence } & \multirow{2}{*}{$\begin{array}{l}\text { 04/30/2012 } \\
9.4 \mathrm{~kW}\end{array}$} \\
\hline POWER & $8.08 \mathrm{kw}$ & Today's Peak: & \\
\hline TODAY & $50.6 \mathrm{kwh}$ & & \\
\hline 30 DAYS & $1,577 \mathrm{kWh}$ & Peak Energy: & $73.4 \mathrm{kWh}$ \\
\hline
\end{tabular}

SYSTEM POWER PLAYBACK

LIVE DATA

STATUS

\section{OK}

2:47 PM

LAST UPDATE

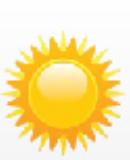

$62^{\circ} \mathrm{F}$

FAN

HELSBOAOUGH, N.

CUMULATIVE SYSTEM ENEFGY: Wh:

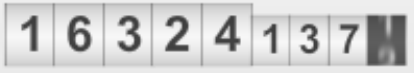

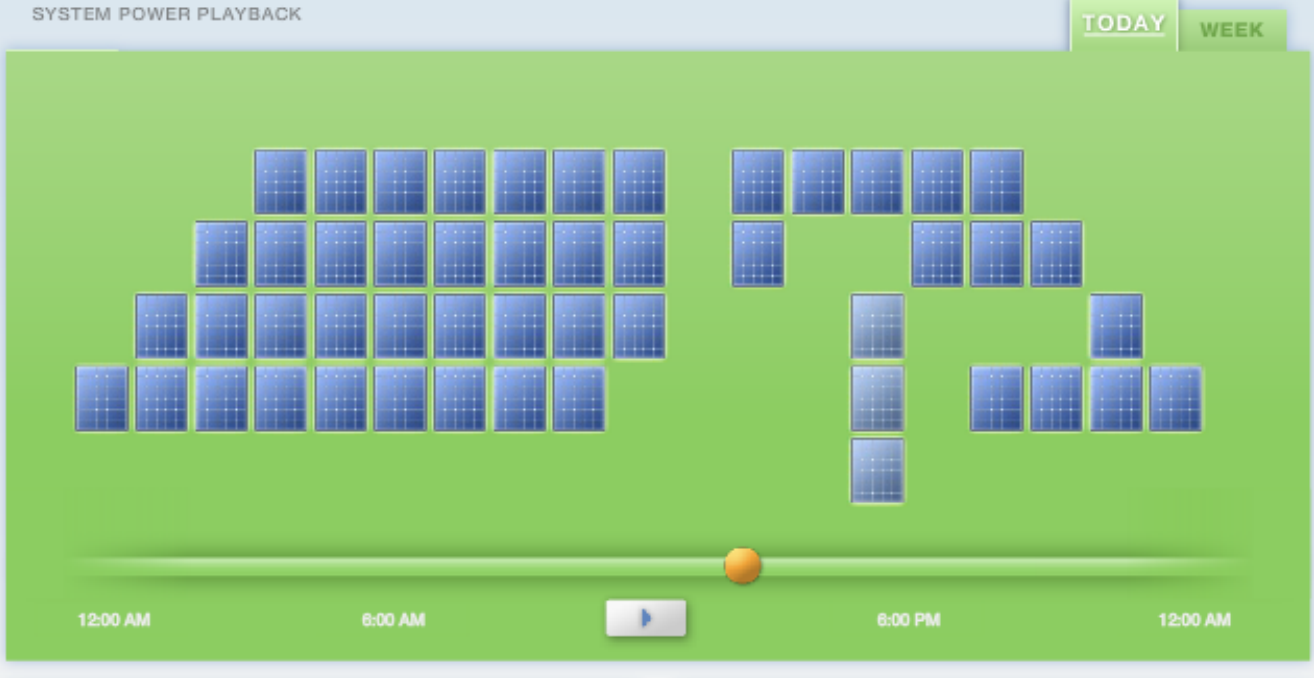

MESSAGES

Your system has been running for 487 doys.

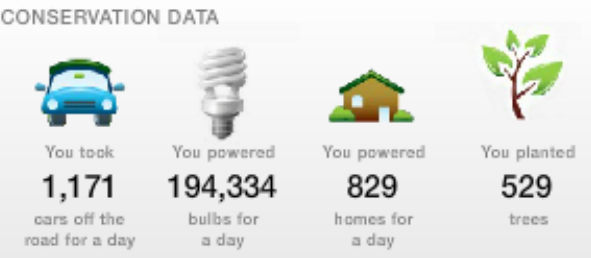

3. Greenflay, Inc. All Rlghts Resenved

2 Park Drive $=1$

Example dashboard display for a system of 50 GreenRay AC Modules in NJ 


\section{Patent Filings}

Over the course of this project, GreenRay filed seven patents in the areas of the inverter, AC module array wiring, the mounting system and data monitoring. The specific patent titles are listed below:

1. Multi-Function Frame and Mounting System for Photovoltaic Power Generating Laminates

2. Data Acquisition Apparatus and Methodology for Self-Diagnosis of AC Modules

3. An Electrical Cable Harness and Assembly for Transmitting AC Electrical Power

4. An Assembly and Method for Mounting Solar Panels to Structural Surfaces

5. An AC Photovoltaic Module and Inverter Assembly

6. Modified Zero Voltage Transition (ZVT) Full Bridge Converter and Photovoltaic (PV) Array Using the Same

7. Hardware Specification for Mounting Photovoltaic Modules to Shingled Surfaces

\section{LCOE}

The thrust of the Solar America Initiative's Technology Pathway Partners program in 2006/7 was to accelerate the reduction in the lifecycle cost of energy (LCOE) for installed PV systems, and achieve parity with conventional sources of grid electricity supply by the year 2015 . In the early stage of the development, projections were made for several different manufacturing volume scenarios. At the conclusion of the development, SG3, the actual manufacturing costs were used and the actual pilot-production volume was assumed. Making a number of assumptions, a projection for 2015 was also calculated. For a residential retrofit PV system in 2015 , the Levelized Cost of Energy target was set at $\$ 0.13-\$ 0.18 / \mathrm{kWh}$. GreenRay used the Solar Advisor Model (SAM) to make the LCOE projections.

To prepare a SAM analysis, the PV system and all relevant technical and financial parameters must be specified. The table below summarizes the assumptions underlying the LCOE projections completed at SG2 and SG3. 
DE-FC36-07G017050

Development of an AC Module System

GreenRay, Inc.

Assumptions used in the LCOE analvsis, at SG2 and SG3.

\begin{tabular}{|c|c|c|c|c|c|}
\hline & $\begin{array}{c}\text { SG2 } \\
2010 \\
\end{array}$ & $\begin{array}{c}\text { SG2 } \\
\text { Med Vol }\end{array}$ & $\begin{array}{c}\text { SG2 } \\
\mathrm{Hi} \mathrm{Vol}\end{array}$ & $\begin{array}{l}\text { SG3 } \\
2011 \\
\end{array}$ & $\begin{array}{l}\text { SG3 } \\
2015 \\
\end{array}$ \\
\hline \multicolumn{6}{|l|}{ SYSTEM } \\
\hline Mounting & Rack & Rack & Rack & Rack & Rack \\
\hline Life (Yrs) & 30 & 30 & 30 & 30 & 30 \\
\hline \multicolumn{6}{|l|}{ ARRAY } \\
\hline Modules per string & 1 & 1 & 1 & 1 & 1 \\
\hline String in parallel & 20 & 20 & 20 & 20 & 20 \\
\hline Array Power (Wdc) & 4200 & 5040 & 5544 & 4208.4 & 6001.2 \\
\hline Inverters & 20 & 20 & 20 & 20 & 20 \\
\hline Total Inverter Power (Wac) & 4240 & 5100 & 5600 & 4200 & 6000 \\
\hline \multicolumn{6}{|l|}{ PERFORMANCE } \\
\hline Pre-inverter derate (soiling) & $98.0 \%$ & $98.0 \%$ & $98.0 \%$ & $98.0 \%$ & $98.0 \%$ \\
\hline Post-inverter derate (ac wiring) & $98.5 \%$ & $98.5 \%$ & $98.5 \%$ & $98.5 \%$ & $98.5 \%$ \\
\hline System Degradation & $0.5 \%$ & $0.5 \%$ & $0.5 \%$ & $0.5 \%$ & $0.5 \%$ \\
\hline \multicolumn{6}{|l|}{ ORIENTATION } \\
\hline Tilt & 18 & 18 & 18 & 18 & 18 \\
\hline Azimuth & 0 & 0 & 0 & 0 & 0 \\
\hline \multicolumn{6}{|l|}{ MODULE } \\
\hline Power (W) & 210 & 252 & 277.2 & 210 & 300 \\
\hline Module Efficiency & $16.7 \%$ & $20.0 \%$ & $22.0 \%$ & $16.7 \%$ & $18.0 \%$ \\
\hline Temperature Coefficient (Pmax) & $-0.25 \%$ & $-0.25 \%$ & $-0.20 \%$ & $-0.25 \%$ & $-0.25 \%$ \\
\hline Structure (glass/cell/polyner) & $\mathrm{g} / \mathrm{c} / \mathrm{p}$ & $g / c / p$ & $\mathrm{~g} / \mathrm{c} / \mathrm{p}$ & $g / c / p$ & $\mathrm{~g} / \mathrm{c} / \mathrm{p}$ \\
\hline Area & 1.26 & 1.26 & 1.26 & 1.26 & 1.667 \\
\hline \multicolumn{6}{|l|}{ INVERTER } \\
\hline Inverter Power (Wac) & 212 & 255 & 280 & 210 & 300 \\
\hline Inverter Efficiency & $91 \%$ & $91 \%$ & $93 \%$ & $91 \%$ & $95 \%$ \\
\hline \multicolumn{6}{|l|}{ COSTS in $2005 \$ s$} \\
\hline Module \$/unit & $\$ 525$ & $\$ 630$ & $\$ 624$ & $\$ 435$ & $\$ 233$ \\
\hline Inverter \$/unit & $\$ 117$ & $\$ 100$ & $\$ 70$ & $\$ 173$ & $\$ 60$ \\
\hline BOS (except inverter) \$/unit & $\$ 41$ & $\$ 16$ & $\$ 12.85$ & $\$ 29$ & $\$ 11.86$ \\
\hline Installation \$/sys & $\$ 6,000$ & $\$ 6,000$ & $\$ 5,000$ & $\$ 7,297$ & $\$ 5,035$ \\
\hline Other/indirect $\$ /$ sys. & $\$ 4,005$ & $\$ 3,804$ & $\$ 3,329$ & $\$ 3,293$ & $\$ 1,579$ \\
\hline Total Installed Cost & $\$ 23,665$ & $\$ 24,724$ & $\$ 22,466$ & $\$ 23,313$ & $\$ 12,717$ \\
\hline Total Installed Cost \$/Wdc & $\$ 5.63$ & $\$ 4.91$ & $\$ 4.05$ & $\$ 5.54$ & $\$ 2.12$ \\
\hline Total/O\&M/kWdc-yr & 24.62 & 24.62 & 8.31 & 50 & 25.42 \\
\hline
\end{tabular}




\section{LCOE for the GreenRay AC Module System}

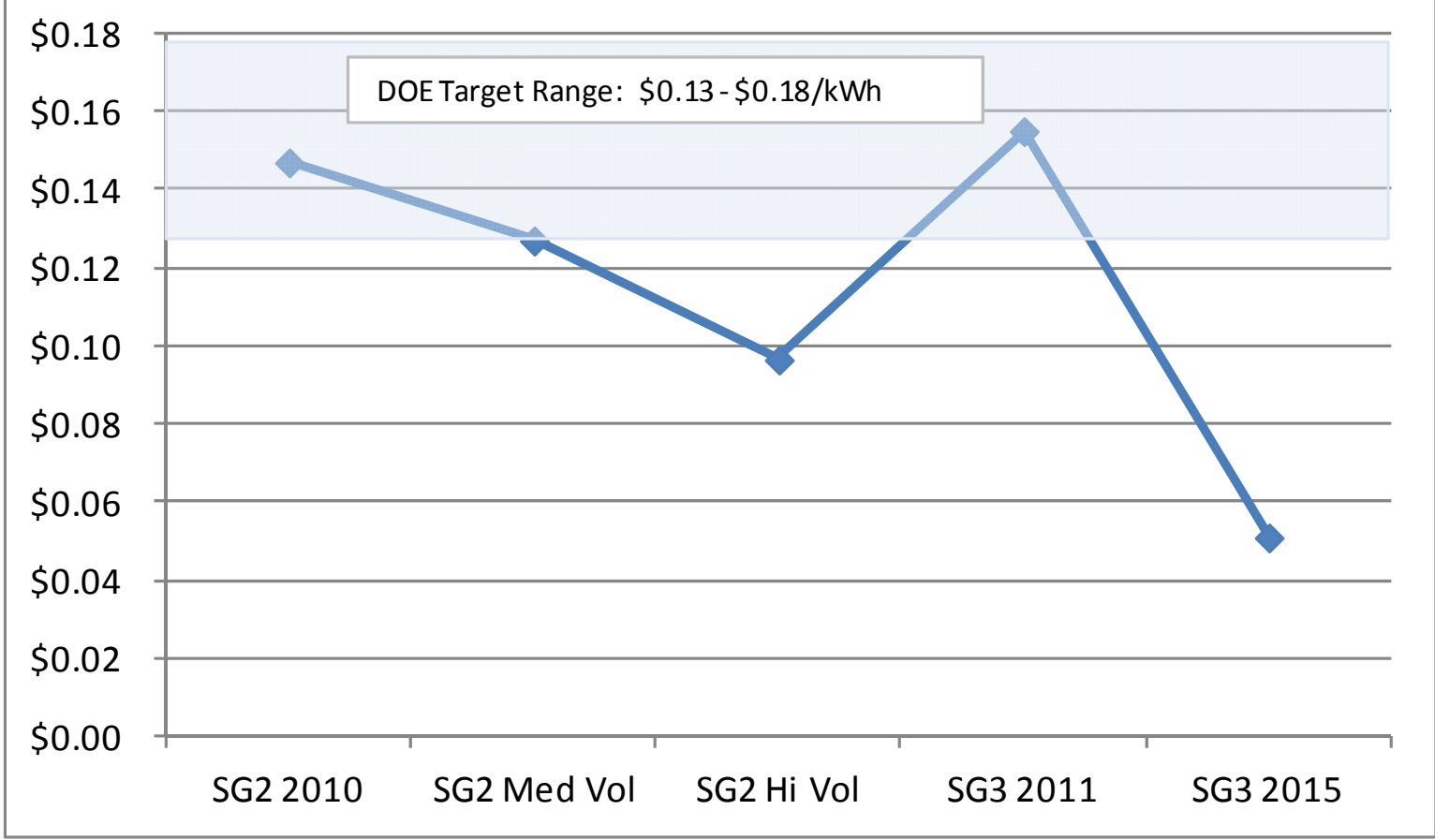

\begin{tabular}{|l|c|c|c|c|c|}
\hline & SG2 2010 & SG2 Med Vol & SG2 Hi Vol & SG3 2011 & SG3 2015 \\
\hline LCOE (\$/kWh) & $\$ 0.147$ & $\$ 0.127$ & $\$ 0.0965$ & $\$ 0.155$ & $\$ 0.051$ \\
\hline DOE Target Range & \multicolumn{5}{|c|}{$\$ 0.13-\$ 0.18$} \\
\hline
\end{tabular}

Note that mature production assumptions underlie the SG3 2015 projections, including manufacturing volume of 500,000 units/year. Trends in the industry show continued improvement in the conversion efficiency of solar cells. Accordingly, in the 2015 scenario a 300-Watt module was assumed. 
DE-FC36-07G017050

Development of an AC Module System

GreenRay, Inc.

\section{Products Developed}

Under this award, several products were developed.

- SunSine AC Module - Incorporates the technology and innovations developed in the high reliability micro-inverter, frame integration and data communications

- Mounting System - The quick mounting system developed for residential roofs

- GreenRay Data Monitoring system - Incorporates the Inverter communications hardware and software, Gateway hardware and software, and customer interface website

- GreenRay company website - Communicates all of these products to the public

The data sheets for each of these products is shown along with the homepage of the GreenRay company website where all of these documents are publicly available. 


\section{NGREenRAY}

\section{SunSine ${ }^{\circledast} 200$ AC Module}

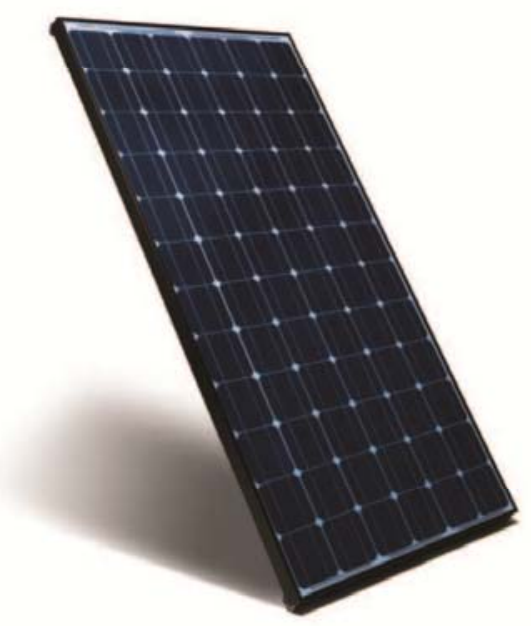

\section{The Ultimate All-in-One Solar Solution}

\section{SIMPLER, MORE RELIABLE SOLAR.}

GreenRay's modular, plug-and-play SunSine ${ }^{\circledR}$ AC Module makes solar more affordable by radically simplifying solar system design and installation.

Simply plug our AC modules together with quick-connect cables and drop into a specially designed roof mount. With fewer components, and faster mounting and wiring, installation has never been easier or safer.

Our all-in-one SunSine ${ }^{\circledast}$ AC Module integrates all the major system components - solar module, micro-inverter, mounting, and monitoring - into a single package, while maximizing energy production and system reliability. So, whether you're considering solar for a home or business, there is no simpler, more reliable system than GreenRay.

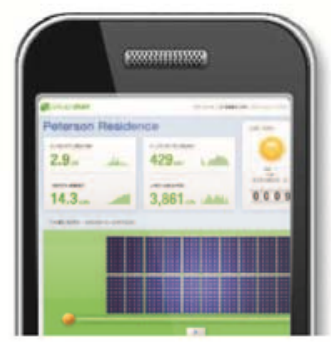

\section{SIMPLER.}

With all of the components integrated at the factory, system design is virtually eliminated. Plus, there are no inverters to mount, no DC wiring, and no cumbersome racks or rails to handle. With $40 \%$ fewer components, simpler mounting, and easier wiring, installation time is cut in half!

\section{MORE RELIABLE.}

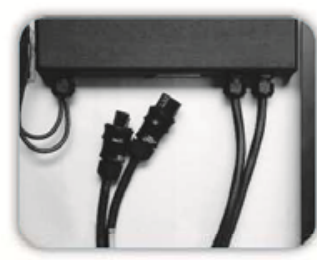

GreenRay's SunSine AC Module is unique in its high reliability and has $3 \mathrm{X}$ the life expectancy of today's inverters through the elimination of weak components. Each module is also individually monitored and performance is easily accessible via any web-enabled device.

\section{MORE POWERFUL.}

The SunSine AC Module produces $5 \%$ to $25 \%$ more energy than typical $\mathrm{PV}$ systems, where one underperforming panel decreases the efficiency of the entire system. Each SunSine ${ }^{6} \mathrm{AC}$ Module operates independently. As a result, energy losses from soiling, shading, and module mismatches are minimized, while energy production is optimized.

GREENRAY I simpler, more reliable solar. For more information, visit us at: www.greenraysolar.com 
DE-FC36-07G017050

Development of an AC Module System

GreenRay, Inc.

SunSine ${ }^{\circledR} 200$ AC Module

DATASHEET

\begin{tabular}{|c|c|c|}
\hline $\begin{array}{l}\text { Maximum Number per 20A } \\
\text { Circuit }\end{array}$ & \multicolumn{2}{|c|}{$\begin{array}{l}10 \text { (120V circuit); } 20 \text { (120/240V } \\
\text { circuit); } 20 \text { (120/208V circuit) }\end{array}$} \\
\hline Warranty & $\begin{array}{l}\text { Inverter: } \\
\text { Module: }\end{array}$ & $\begin{array}{l}20 \text { yrs } \\
5 \text { yrs - workmanship, } \\
20 \text { yrs - power }\end{array}$ \\
\hline Ambient Temp. ${ }^{1}$ & \multicolumn{2}{|c|}{$-4^{\circ} \mathrm{F}$ to $115^{\circ} \mathrm{F}\left(-20^{\circ} \mathrm{C}\right.$ to $\left.46^{\circ} \mathrm{C}\right)$} \\
\hline Utility Connect & \multicolumn{2}{|c|}{5 min turn-on delay } \\
\hline Hail Safety Impact Velocity & \multicolumn{2}{|c|}{ 1" (25mm)@ $52 \mathrm{mph}(23 \mathrm{~m} / \mathrm{s})$} \\
\hline NOCT & \multicolumn{2}{|c|}{$114.8^{\circ} \mathrm{F}\left(46^{\circ} \mathrm{C}\right)$} \\
\hline Communication & \multicolumn{2}{|l|}{ Powerline } \\
\hline \multicolumn{3}{|c|}{ ELECTRICAL SPECIFICATIONS } \\
\hline \multicolumn{2}{|c|}{$\begin{array}{l}\text { Maximum AC Power } \\
\left.\text { [Module Rated DC Power, STC }{ }^{3}\right]\end{array}$} & $\begin{array}{l}200 W \pm 5 \% \\
{[210 W]}\end{array}$ \\
\hline \multicolumn{2}{|l|}{ Nominal AC Voltage } & $120 \mathrm{~V}$ \\
\hline \multicolumn{2}{|c|}{ Operating Utility AC Voltage Range ${ }^{2}$} & $107-131 \mathrm{~V}$ \\
\hline \multicolumn{2}{|l|}{ Maximum AC Output Current } & $1.6 \mathrm{~A}$ \\
\hline \multicolumn{2}{|l|}{ Nominal AC Frequency } & $60 \mathrm{~Hz}$ \\
\hline \multicolumn{2}{|c|}{ Operating Utility Frequency Range ${ }^{2}$} & $59.4-60.4 \mathrm{~Hz}$ \\
\hline \multicolumn{2}{|c|}{ Total Harmonic Distortion (THD) } & $<5 \% \max$ \\
\hline \multicolumn{2}{|l|}{ Power Factor ( $100 \%$ Power) } & 0.98 \\
\hline \multicolumn{2}{|c|}{ Efficiency: Sunlight to AC Power, STC ${ }^{3}$} & $15.3 \%$ \\
\hline \multicolumn{3}{|c|}{$\begin{array}{l}{ }^{1} \text { Monthly average low and high temperatures at the installation site } \\
{ }^{2} \text { Adjustable }\end{array}$} \\
\hline \multicolumn{3}{|c|}{${ }^{3}$ Standard Test Conditions: Cell temp. $25^{\circ} \mathrm{C}$, AM1.5, $1000 \mathrm{~W} / \mathrm{m}^{2}$} \\
\hline
\end{tabular}

MOUNTING AND WIRING

Residential Mounting: GreenRay Quick Mount - eliminates traditional racking hardware

Gap Between Adjacent Modules: 0.5"

Gap Between Adjacent Rows: 2.25"

Ground Wiring: UL approved, equipment ground carried by

module frames and mounting - No ground wires required

Module - to -Module AC Wiring: 3-position, fully-guarded,

locking AC-connector

Automatic balancing of power across phases of $120 / 240 \mathrm{~V}$ and $120 / 208 V$ electrical service

\section{MECHANICAL SPECIFICATIONS}

\begin{tabular}{ll} 
Dimensions [in $(\mathrm{mm})]$ & $62.7 \times 31.4 \times 1.8(1590 \times 798 \times 46)$ \\
\hline Weight [lbs $(\mathrm{kg})]$ & $44.0(20.0)$ \\
\hline Static Load Wind / Snow & $60 \mathrm{PSF} / 39 \mathrm{PSF}$ \\
\hline Fire Safety Classification & Class C \\
\hline Cells & 72 series, 5 -inch high efficiency cells \\
\hline Module Area & $13.67 \mathrm{ft}^{2}\left(1.27 \mathrm{~m}^{2}\right)$
\end{tabular}

\section{CERTIFICATIONS}

PV Module: UL 1703, cUL, CEC

Micro-Inverter: UL 1741

SunSine AC Module (PV Module and Integrated Micro-Inverter): UL 1741, IEEE 1547, FCC Part 15 Class B

\section{*US Patents Pending*}
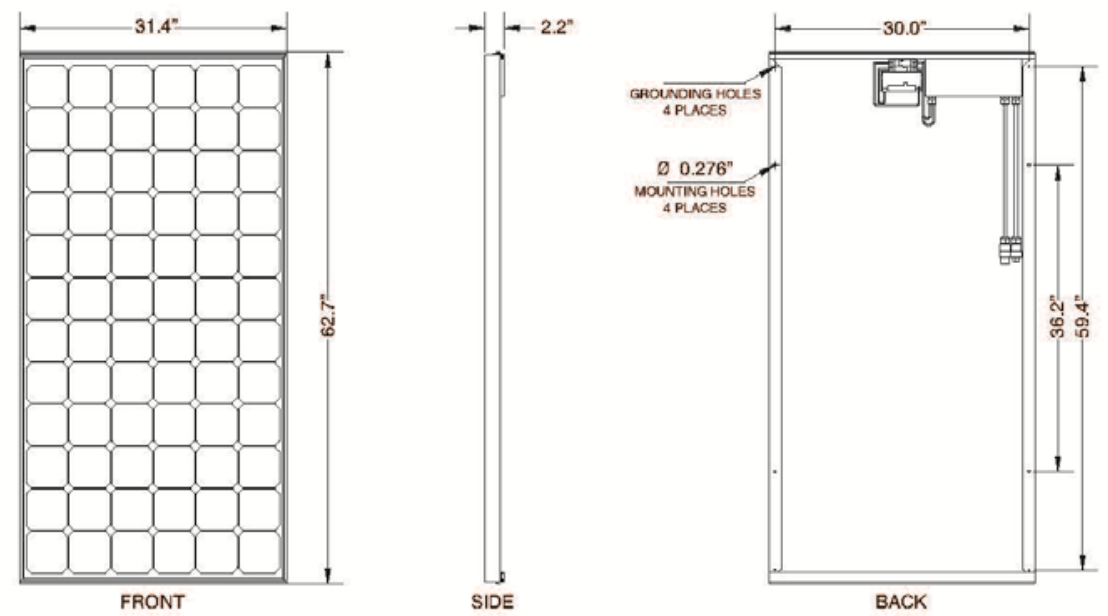

GreenRay, Inc.

2 Park Drive, Suite 1, Westford, MA 01886

978.631.0509 I info@greenraysolar.com www.greenraysolar.com

(1) GreenRay, Inc. 2010 - Specifications and information above may change without notice. 


\section{NGREenRAY}

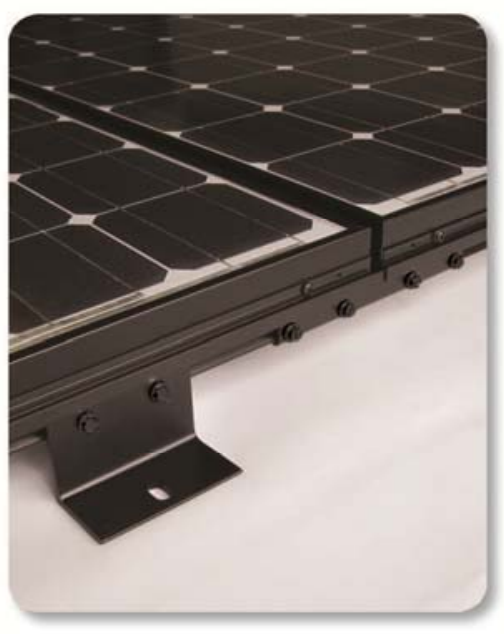

\section{GreenRay Mounting Solution} for the SunSine ${ }^{\mathrm{TM}} 200$ AC Module

\section{SIMPLER, MORE RELIABLE SOLAR}

GreenRay's proprietary mounting solution dramatically simplifies installation of our plug-and-play SunSine ${ }^{\text {TM }} 200$ AC Module, while enhancing system reliability and safety. Our mounting system is fully integrated with the module frame and installs in half the time of conventional rack-mounted systems - with $40 \%$ fewer parts, no cumbersome rails, and no special tools required. Aluminum mounting feet and link plates connect easily to the module frame and automatically bond the array for trouble-free grounding. The result: lower cost of installation, and a safer, more reliable and attractive system.

\section{KEY TECHNICAL FEATURES}

Suitable for $130 \mathrm{mph}$ wind zones per ASCE 7-05

Frame adapter ETL tested to UL1703 as ground bond means

Link Plates and J Box ETL tested to UL467 as grounding and bonding device

Compatible with majority of attachment solutions for composition shingle, tile, and metal roofs

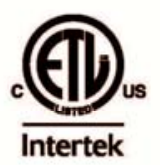

\section{FASTER INSTALLATION}

- Speeds installation by $2 X$ or more

- Dramatically reduces installation cost

- Eliminates mounting rails and clips

- Eliminates complex parts and special tools

- Enables easy replacement of a single module

IMPROVED SAFETY \& RELIABILITY

- Provides robust, ETL approved auto-grounding design

- Eliminates separate grounding hardware

- Promotes worker safety on sloped roofs

MORE ATTRACTIVE

- Improved aesthetics with lower profile

- Automatic spacing between rows and modules

- Prevents debris build-up and water trapping 
DE-FC36-07G017050

Development of an AC Module System

GreenRay, Inc.

\begin{tabular}{ll}
\hline Component & Part No. \\
\hline North Foot & MT-AB-01 \\
\hline
\end{tabular}

Weight
$8.0 \mathrm{oz}$

The north foot provides an attachment point between the module and roof surface or flashing system and fixes the spacing between rows.

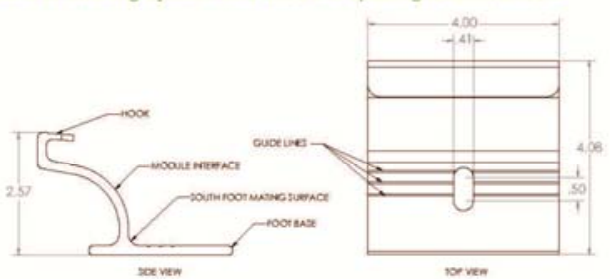

\begin{tabular}{|l|l|}
\hline Component & Part No. \\
\hline South Foot & MT-AD-01 \\
\hline
\end{tabular}

Weight

The south foot provides a low-profile attachment point between the module and roof surface or flashing system.

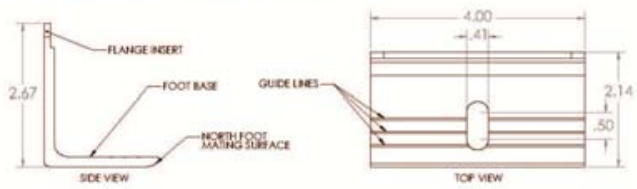

\begin{tabular}{|lll|}
\hline Component & Part No. & Weight \\
\hline Exterior Link Plate & MT-AE-01 & $2.2 \mathrm{oz}$ \\
\hline
\end{tabular}

The exterior link plate fixes spacing between modules, provides east-west structural support and creates the ground bond between modules.
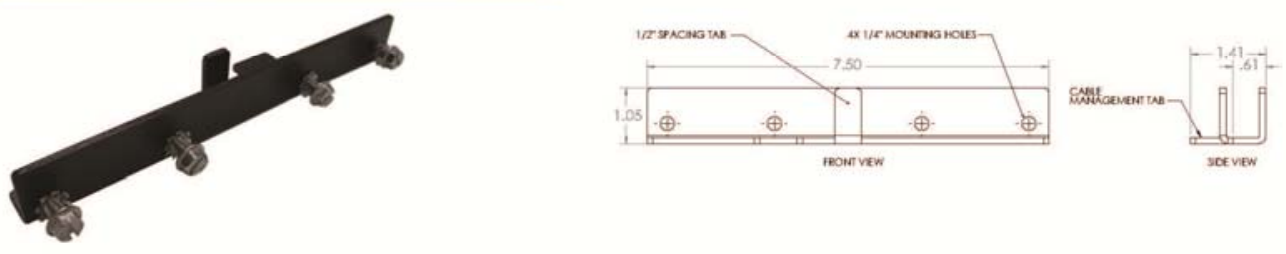

\begin{tabular}{lll}
\hline Component & Part No. & Weight \\
\hline Interior Link Plate & MT-AI-01 & $8.0 \mathrm{oz}$ \\
\hline
\end{tabular}

The interior link plate fixes spacing between modules, provides east-west structural support and creates the ground bond between modules.
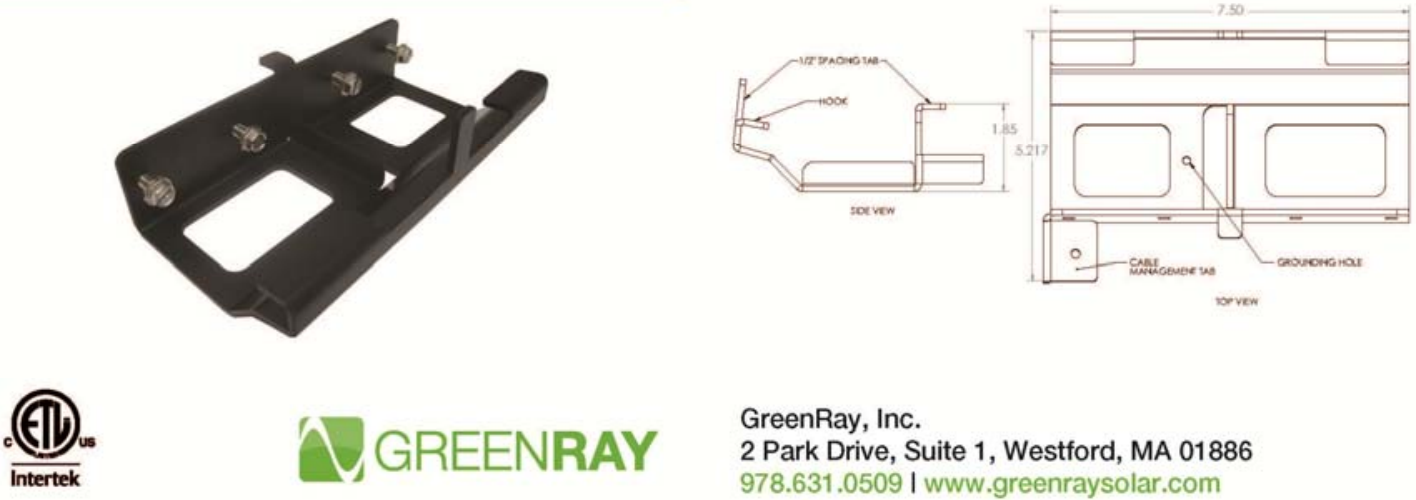

GreenRay, Inc.

2 Park Drive, Suite 1, Westford, MA 01886

978.631.0509 I www.greenraysolar.com

(c) GreenRay, Inc. 2010 - Specifications and information above may change without notice. 
DE-FC36-07G017050

Development of an AC Module System

GreenRay, Inc.

\section{NGREENRAY}

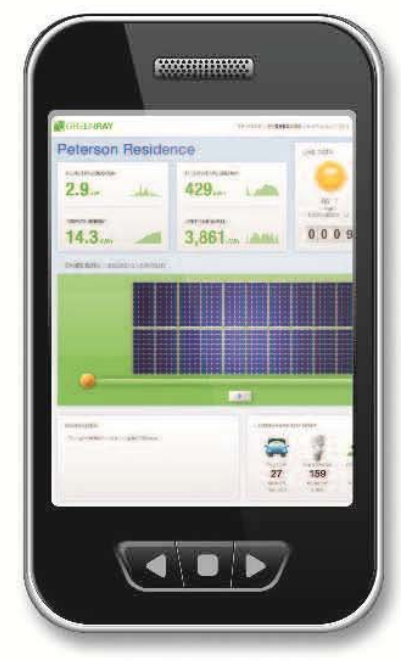

\section{GreenRay SunTrak ${ }^{\text {Tm }}$}

\section{Monitoring System for SunSine ${ }^{\mathrm{TM}} 200$ AC Modules}

\section{SIMPLER, MORE RELIABLE SOLAR}

The GreenRay SunTrak ${ }^{T m}$ Monitoring System tracks details on the performance of the entire solar system. Unlike monitoring systems for traditional solar systems, the SunTrak ${ }^{\mathrm{Tm}}$ Monitoring System also analyzes the performance of individual SunSine ${ }^{T M} A C$ Modules for greater reliability. Flexible architecture displays the information from any web-enabled device. The result: a simpler, more reliable way to monitor your system and maintain optimal performance.

\section{KEY TECHNICAL FEATURES}

Get Info on the Go

See how a system is doing from the comfort of your computer or on the go with your iPhone or Blackberry.

Track Performance View the total energy generated, as well as details on how each module is performing.

Maximize Your Returns Obtain optimal energy production from your solar investment. Each AC Module monitors its own health and sends an alert if there is a problem.

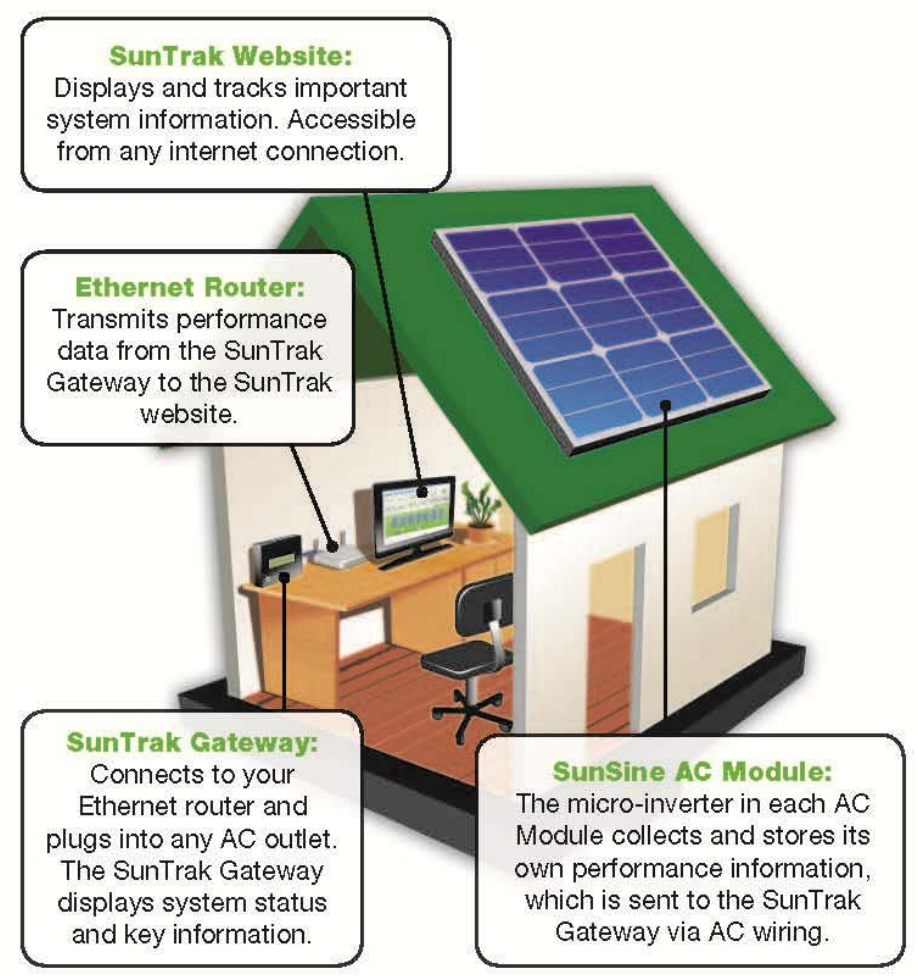

GREENRAY I simpler, more reliable solar. For more information, visit us at: www.greenraysolar.com 
DE-FC36-07G017050

Development of an AC Module System

GreenRay, Inc.

GreenRay SunTrak ${ }^{\mathrm{TM}}$ Monitoring System for SunSine ${ }^{\mathrm{TM}} 200$ AC Modules

DATASHEET

The SunTrak website offers a powerful information and system management tool for both homeowners and installers.

This intelligent monitoring system automatically sends alerts and pinpoints the specific module needing maintenance.

Problems can be quickly addressed that could otherwise go unnoticed in traditional systems that do not monitor individual modules and reduce system performance. This also eliminates the lengthy onsite troubleshooting time to determine which module is having a problem.

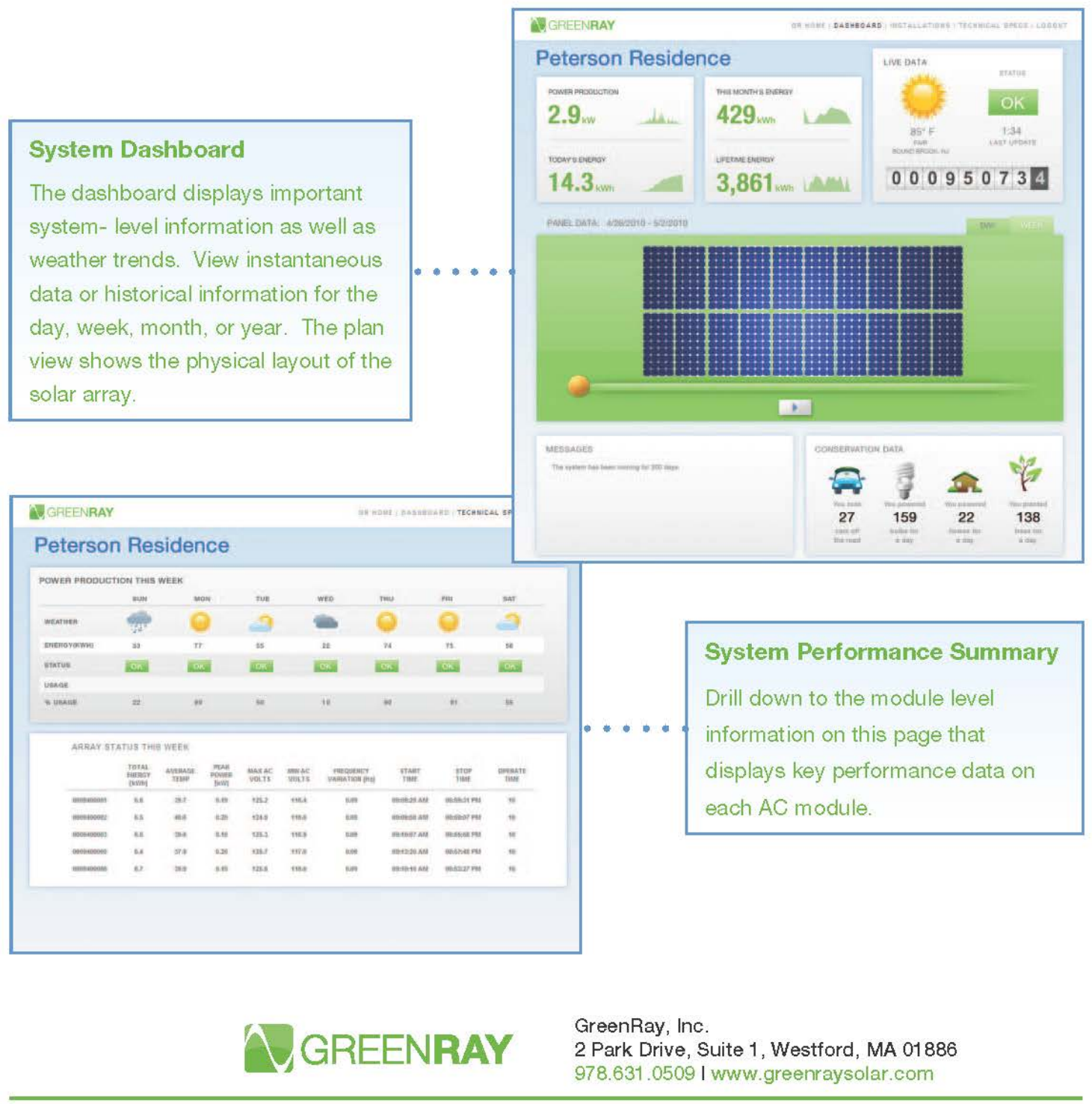

(1) GreenRay, Inc. 2010 - Specifications and information above may change without notice. 
DE-FC36-07G017050

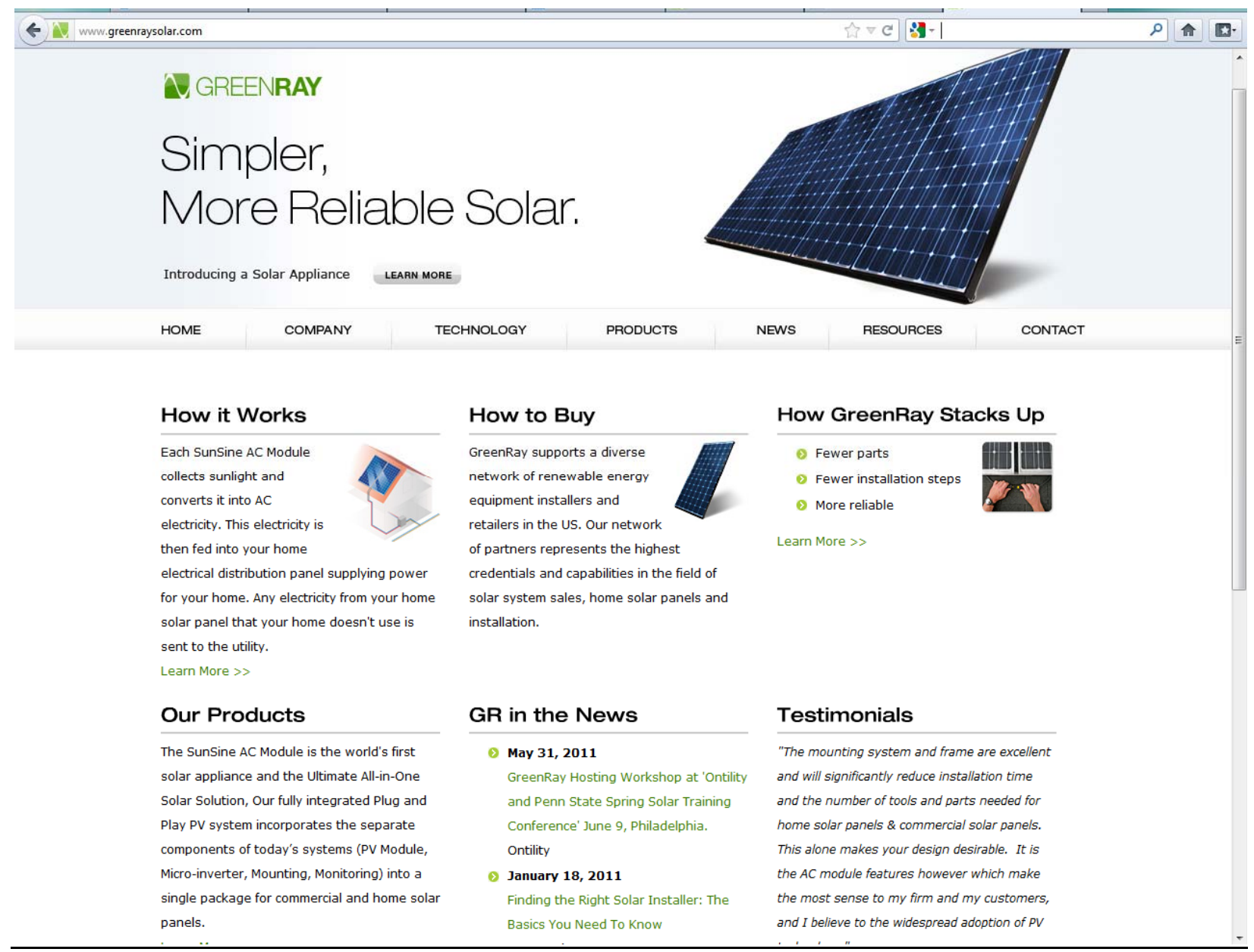

